Published as:

Al-Damegh, K., Sandvol, E., and Barazangi, M., 2005. Crustal structure of the Arabian plate: New constraints from the analysis of teleseismic receiver functions, Earth Planet. Sci. Lett., 231, 177-196.

\title{
Crustal structure of the Arabian plate: New constraints from the analysis of teleseismic receiver functions
}

Khaled Al-Damegh ${ }^{\mathrm{a}, \mathrm{b}}$, Eric Sandvol ${ }^{\mathrm{c}}$, Muawia Barazangi ${ }^{\mathrm{a}}$

${ }^{a}$ Institute for the Study of the Continents and Department of Earth and Atmospheric Sciences, Cornell University, Snee Hall, Ithaca, New York 14853, USA

${ }^{\mathrm{b}}$ Currently at the Astronomy and Geophysics Research Institute, King Abdulaziz City for Science and Technology, P.O. Box 6086, Riyadh 11442, Saudi Arabia

c Department of Geological Sciences, University of Missouri, 101 Geology Building, Columbia, Missouri 65211, USA

Corresponding author: $\quad$ Dr. Muawia Barazangi

Institute for the Study of the Continents

Snee Hall

Cornell University

Ithaca, NY 14853

USA

Tel. (607) 255-6411

Fax. (607) 254-4780

e-mail: mb44@cornell.edu

Words Count: 5653 


\begin{abstract}
Receiver functions for numerous teleseismic earthquakes recorded at 23 broadband and midband stations in Saudi Arabia and Jordan were analyzed to map crustal thickness within and around the Arabian plate. We used spectral division as well as time domain deconvolution to compute the individual receiver functions and receiver function stacks. The receiver functions were then stacked using the slant stacking approach to estimate Moho depths and $\mathrm{Vp} / \mathrm{Vs}$ for each station. The errors in the slant stacking were estimated using a bootstrap re-sampling technique. We also employed a grid search waveform modeling technique to estimate the crustal velocity structure for seven stations. A jackknife re-sampling approach was used to estimate errors in the grid search results for three stations. In addition to our results, we have also included published receiver function results from two temporary networks in the Arabian shield and Oman as well as three permanent GSN stations in the region.
\end{abstract}

The average crustal thickness of the late Proterozoic Arabian shield is $39 \mathrm{~km}$. The crust thins to about $23 \mathrm{~km}$ along the Red Sea coast and to about $25 \mathrm{~km}$ along the margin of the Gulf of Aqaba. In the northern part of the Arabian platform, the crust varies from 33 - $37 \mathrm{~km}$ thick. However, the crust is thicker $(41-53 \mathrm{~km})$ in the southeastern part of the platform. There is a dramatic change in crustal thickness between the topographic escarpment of the Arabian shield and the shorelines of the Red Sea. We compared our results in the Arabian shield to nine other Proterozoic and Archean shields that include reasonably well-determined Moho depths, mostly based on receiver functions. The average crustal thickness for all shields is $39 \mathrm{~km}$, while the average for Proterozoic shields is $40 \mathrm{~km}$, and the average for Archean shields is $38 \mathrm{~km}$. We found the crustal thickness of Proterozoic shields to vary between 33 and $44 \mathrm{~km}$, while Archean shields vary between 32 and $47 \mathrm{~km}$. Overall, we do not observe a significant difference between Proterozoic and Archean crustal thickness. 
We observed a dramatic change in crustal thickness along the Red Sea margin that occurs over a very short distance. We projected our results over a cross section extending from the Red Sea ridge to the shield escarpment and contrasted it with a typical Atlantic margin. The transition from oceanic to continental crust of the Red Sea margin occurs over a distance of about $250 \mathrm{~km}$, while the transition along a typical portion of the western Atlantic margin occurs at a distance of about $450 \mathrm{~km}$. This important new observation highlights the abruptness of the breakup of Arabia. We argue that a preexisting zone of weakness coupled with anomalously hot upper mantle could have initiated and expedited the breakup.

Keywords: crustal structure; receiver functions; Arabian plate; Red Sea 


\section{Introduction}

The Arabian plate consists of a late Proterozoic shield bounded to the east by a Phanerozoic platform and separated from the African plate by a very young spreading center located within the Red Sea and the Gulf of Aden (Fig. 1). The shield consists of a series of Proterozoic accreted island arc terrains that were assembled during several subduction episodes [1]. The Arabian/Nubian shields were separated by a rifting process that started in Afar and propagated eastward and northward creating the Gulf of Aden and the Red Sea, respectively [2]. The Arabian shield is generally elevated with respect to the Arabian platform and is marked along its western boundary by an escarpment reaching more than $2000 \mathrm{~m}$ in some places. The platform overlaps the eastern part of the shield unconformably and consists of thick Paleozoic and Mesozoic sedimentary layers dipping eastward and reaching $10 \mathrm{~km}$ or more in thickness [3-5].

It appears that the Red Sea consists of both oceanic and attenuated/thinned continental crust $[6,7]$. Neogene and Quaternary volcanics are present along the western part of the Arabian plate [8]. The Dead Sea fault system is located along the northwestern boundary of the Arabian plate. The fault is left lateral with a minor component of rotation that results in the development of pull-apart basins, such as the Dead Sea rift basin [9]. The Mesopotamian foredeep, which is located to the west of the Zagros fold and thrust belt, consists of thick sediments that increase in thickness toward the Zagros belt [10].

Two large seismic experiments have been conducted in the Arabian shield. A deep refraction line was shot in 1978. More recently a temporary deployment of broadband seismic stations was deployed in central Saudi Arabia. Both of these experiments were primarily focused on the southern part of the shield and ran from near the Red Sea coast to the western portion of the platform. Results from both experiments suggest that the Arabian shield has an average crustal 
thickness of $40 \mathrm{~km}$, thinning rapidly near the Red Sea coast and gradually increasing toward the platform [11-14]. Specifically in the Arabian platform, Al-Amri [15, 16] reported a 46 km thick crust under RIYD station (Fig. 2) and $51 \mathrm{~km}$ near the Arabian/Persian Gulf using teleseismic body wave spectra. In Oman, southeast of RIYD station, the crust is about 41 - 49 km thick [17]. In the northern and northwestern part of the platform, the crust seems to vary between 33 and 40 $\mathrm{km}$ [18-21]. Surface waves as well as regional waveform modeling indicate that on average the Arabian shield crust is 40 - $45 \mathrm{~km}$ thick, slightly thicker than the average crust for most shields on earth [22-24]. Also, slower-than-average $\mathrm{P}$ and $\mathrm{S}$ velocities were found in the uppermost mantle beneath the western part of the shield [25, 26], indicating the upper mantle is anomalously hot and is possibly associated with the uplift of the Arabian shield [26, 27]. The low velocity anomaly was found to extend from the Red Sea eastward into the interior of the shield and to be confined to depths shallower than $410 \mathrm{~km}$ [26].

Seismic receiver functions are typically used to image the depth to major velocity discontinuities in the crust and uppermost mantle. Lateral variation of crustal thickness in a region is an important parameter in understanding the geologic and tectonic processes that have been dominant in the region. This study makes use of a new waveform database produced by a recently established permanent broadband seismic array in Saudi Arabia [28] as well as 2 intermediate band permanent stations in Jordan [20]. This database provided us with the opportunity to use teleseismic receiver functions to map the crustal thickness and crustal $\mathrm{Vp} / \mathrm{Vs}$ in the Arabian plate. 


\section{Data}

The data used in this study consist primarily of teleseismic recordings from 21 broadband permanent stations in Saudi Arabia and 2 intermediate-band temporary stations in Jordan (see Fig. 2). The broadband stations in Saudi Arabia have been deployed by King Abdulaziz City for Science and Technology (KACST) since mid 1998, and the data are transmitted to a central station via dedicated phone lines [28]. The data from Jordan span a period of approximately two years and were deployed jointly with the United States Geological Survey (USGS), the Jordan Seismological Observatory (JSO), and the Lawrence Livermore National Laboratory (LLNL) [20]. These combined 23 stations span a large region across the western Arabian plate; although a majority are located within the Arabian shield. Table 1 lists the location of stations used in this study. Both networks recorded continuously with a high sampling rate (100 Hz for the Saudi stations and $50 \mathrm{~Hz}$ for the Jordanian stations). We used the USGS/PDE monthly catalog times to associate and window teleseismic seismograms with distances between 35 and 85 degrees. The first arrival waveforms were windowed and sub-sampled to $20 \mathrm{~Hz}$. We have also included in our study proximal published receiver function results in the region from Sandvol et al. [13, 19], and Al-Lazki et al. [17]. These studies utilized seismic data from temporary networks in Saudi Arabia and Oman in addition to permanent GSN stations in the region. 


\section{Methods}

$\mathrm{P}$ to $\mathrm{S}$ converted phases originating from near receiver velocity discontinuities have been used to infer crustal and upper mantle structure for the past 30 years (e.g. [29, 30]) (see Fig. 3). Receiver functions are calculated by de-convolving the vertical from the radial and tangential components and are used to isolate and identify $\mathrm{P}$ to $\mathrm{S}$ converted phases. The time delay between the first arriving direct wave and the associated converted phases is a function of the depth and velocity structure of the medium. We have calculated receiver functions in this study using both spectral deconvolution [29] and time domain methods [31]. We observed very little difference in the receiver functions generated by both methods, indicating that the deconvolution is relatively stable. We have applied a Gaussian low pass filter with a corner frequency of 0.5 $\mathrm{Hz}$ to all our receiver functions. Using the time difference between the $\mathrm{PS}_{\text {Moho }}$ phase and the first arrival, the depth to Moho can be estimated based on the following equation:

$$
\mathrm{H}=\mathrm{t}_{\mathrm{ps}} /\left(\left(1 / \mathrm{Vs}^{2}-\mathrm{p}^{2}\right)^{1 / 2}-\left(1 / \mathrm{Vp}^{2}-\mathrm{p}^{2}\right)^{1 / 2}\right)
$$

where $\mathrm{H}$ is the depth to Moho, $\mathrm{t}_{\mathrm{ps}}$ is the time delay between the first arrival and the Moho phase, Vs is the $\mathrm{S}$ wave velocity, $\mathrm{Vp}$ is the $\mathrm{P}$ wave velocity, and $\mathrm{p}$ is the ray parameter.

However, since the delay time of the S leg is dependent on the shear velocity of the medium, the crustal thickness trades off strongly with the seismic wave velocity [32]. Incorporating multiply reflected phases such as PsPs and PpSs+PsPs (Fig. 3) helps reduce this

trade off significantly. The time delays ( $t_{\mathrm{PpPs}}$ and $\mathrm{t}_{\mathrm{PPSs}}+\mathrm{PsPs}$ ) for PsPs and PpSs+PsPs phases and $\mathrm{H}$ can be expressed in the following equations:

$$
\mathrm{H}=\mathrm{t}_{\mathrm{ppPs}} /\left(\left(1 / \mathrm{Vs}^{2}-\mathrm{p}^{2}\right)^{1 / 2}+\left(1 / \mathrm{Vp}^{2}-\mathrm{p}^{2}\right)^{1 / 2}\right)
$$




$$
\mathrm{H}=\mathrm{t}_{\mathrm{PpSs}+\mathrm{PsPs}} / 2\left(1 / \mathrm{Vs}^{2}-\mathrm{p}^{2}\right)^{1 / 2}
$$

To further enhance the signal/noise ratio and reduce lateral variations, multiple receiver functions are stacked in the time domain. Zhu and Kanamori [32] developed a straightforward approach that adds the amplitudes of the $\mathrm{PS}_{\text {Moho }}$ and multiples at the predicted time by varying $\mathrm{H}$ (crustal thickness) and the Vp/Vs. This "slant stacking” approach essentially transforms the receiver function stacks from the time domain to the $\mathrm{H}-\mathrm{Vp} / \mathrm{Vs}$ domain. The $\mathrm{H}-\mathrm{Vp} / \mathrm{Vs}$ domain stacking is defined by:

$$
\mathrm{S}(\mathrm{H}, \mathrm{Vp} / \mathrm{Vs})=\mathrm{w}_{1} \mathrm{r}\left(\mathrm{t}_{\mathrm{ps}}\right)+\mathrm{w}_{2} \mathrm{r}\left(\mathrm{t}_{\mathrm{PpPs}}\right)-\mathrm{w}_{3} \mathrm{r}\left(\mathrm{t}_{\mathrm{PpSs}}+\mathrm{PsPs}_{\mathrm{P}}\right)
$$

where the $r\left(t_{p s}\right)$ is the amplitude of the receiver function at the time $t_{p s}$ and $w_{1}, w_{2}$, and $w_{3}$ are the weighting factors that sum to unity. The main advantage of this technique is that there is no need to pick the arrival times of the Moho or the multiples, making this technique more objective than having to manually identify these various phases. This approach also removes the effects of different ray parameters (p) on the moveout of the listed P-to-S converted phases. Based on many trials in our slant stacking analysis, we found that the most suitable weighting factors that balance the contribution of each phase were $0.40,0.35$, and 0.25 for $\mathrm{w}_{1}, \mathrm{w}_{2}$, and $\mathrm{w}_{3}$, respectively. These weights were proportional to the signal/noise ratios for the three phases. We used the same weighting factors for most of the stations in this study. When certain phases were not observed, we were forced to modify our default weighting factors. In these few cases we used weightings of $0.8,0.0,0.2$ for $\mathrm{w}_{1}, \mathrm{w}_{2}, \mathrm{w}_{3}$, respectively. We have documented these special cases in the Results section. 
We have used the bootstrap re-sampling technique to test the stability of our slant stacking results. We re-sampled our data by randomly selecting individual receiver functions to create a set of 100 or more bootstrapped receiver function stacks. We used these bootstrapped receiver functions to estimate the 2 standard deviations for $\mathrm{H}$ and $\mathrm{Vp} / \mathrm{Vs}$ for the trials. This approach was used for all 23 stations.

We have also used the grid search waveform modeling technique developed by Sandvol et al. [19] to estimate shear wave velocity structure for seven stations, both to validate our results and to compare the results of the two techniques. The grid search technique searches over a wide range of model parameters in order to find the 1-D velocity model that optimally fits the radial receiver function waveforms. The number of model parameters is limited by assuming a Poisson ratio. This approach requires that a region of model parameter space be chosen for the grid search; typically we began with 2- 4 layers and increased the number of layers when it was required to reasonably fit the waveform. The range of model parameters that were used in the search was based on prior studies of the structure of the region and/or through trial and error. This modeling technique uses a reflectivity synthetic seismogram algorithm, initially developed by Kennett [33], to generate synthetic receiver functions that are compared with observed stacked receiver functions. The best fit is found by minimizing the least square difference between the observed and the synthetic receiver functions.

In order to test the stability of our grid search solutions, we performed a jackknife data re-sampling for the FRSS, KBRS, and TAYS receiver functions. This technique has the advantage of not requiring the estimation of a noise time series and also has been proven to yield unbiased and robust error estimates for nonlinear inversions [34, 35]. However, neither of our resampling error estimation techniques is sensitive to systematic errors in the data. One way to 
overcome this drawback is comparison of our Moho depths with other published results in the region.

\section{Results}

We have organized our discussion of our results into four groups based on the tectonic environment and location. These four regions include the Arabian shield (specifically stations KBRS, TBKS, NAMS, HILS, BLJS, DJNS, TATS, ARSS, AFFS), the Gulf of Aqaba (specifically stations AYUS, BDAS, TAYS, HAQS, ALWS, JMQS, JMQS, HITJ), the Arabian platform (stations HASS, RUWJ, QURS), and the Red Sea (stations FRSS, YNBS, LTHS). Our results for all the stations are listed in Table 1 . We will also show the results for all stations in a special web site.

\subsection{Stations within the Arabian shield}

KBRS: In general, the Arabian shield stations are characterized by lower noise than the other stations in the Arabian Peninsula. We slant stacked 30 receiver functions (Fig. 4b) in order to find the bulk crustal thickness and crustal Vp/Vs. We observed clear arrivals of $\mathrm{PS}_{\text {Moho }}$ and multiples at KBRS (Fig. 4c). We estimated a Moho depth of $35.2 \mathrm{~km}$ and a Vp/Vs of 1.75. We have also performed a 4 layer grid search inversion for KBRS and we obtained a 35.5 km (Fig. 4e) depth for the Moho using the grid search (Fig. 4d, e). The two values for the Moho depth are extremely close, probably owing to the nearly 1-D velocity structure beneath this station. The 2 standard deviation (STD) for 100 bootstrap error analysis shows $\pm 1.0 \mathrm{~km}$ in Moho depth and \pm 0.038 for the $\mathrm{Vp} / \mathrm{Vs}$. 
TBKS: We have good azimuthal coverage for this station (see the electronic supplement). We observed a clear crossing of Moho phase and multiples from the slant stacking of 32 receiver functions (see the electronic supplementary Fig. S1). We observed a clear multiple at 8 seconds, labeled as Pxs in the electronic supplementary Fig S1, for events with a distance range of greater than $60^{\circ}$. If this is not a multiple, then this arrival could be associated to a velocity discontinuity at a depth of about $75 \mathrm{~km}$.

NAMS: NAMS is located in the western part of the shield along the $2 \mathrm{~km}$ escarpment. From the slant stacking of 42 receiver functions we observed a crustal thickness of $42 \pm 2 \mathrm{~km}$ with a Vp/Vs of $1.69 \pm 0.03$ (Fig. 5). We also noticed a coherent multiple around 2 seconds, labeled Pxs in Fig. 5c, that could be due to a major mid crustal discontinuity at about $16 \mathrm{~km}$ depth.

HILS: This is one of the best stations used in this study. We have been able to utilize 55 receiver functions for the slant stacking approach (see the electronic supplementary Fig. S2). We estimate the Moho depth to be $36.9 \pm 1.0 \mathrm{~km}$ with a $\mathrm{Vp} / \mathrm{Vs}$ of $1.78 \pm 0.02$. Although these error values cannot be used as a measure of absolute error, the values reflect the quality and stability of the data used. We have also performed a grid search inversion over 4 layers for HILS and we obtained a Moho depth of $39.5 \mathrm{~km}$, which is in close agreement with our slant stacking result. We expect the difference to be caused by the sampling of the grid search compared to utilizing the whole data set in slant stacking.

Crustal thickness results for other stations in the shield including BLJS, DJNS, TATS, and ARSS, are listed in Table 1 and shown in Figures 2 and 8. We observed complex receiver function waveforms at DJNS. We applied both slant stacking and grid search techniques to 
obtain a Moho depth of $44 \mathrm{~km}$ and $47 \mathrm{~km}$, respectively. Higher than average Vp/Vs ratios of 1.83 for the slant stacking and 1.8 for the grid search were also observed. We suspect that the complexity in the receiver function may be due to the lateral variations in the velocity structure originating from the nearby active volcanic centers. We observed a coherent multiple arriving before the Moho phase (around 2-3 seconds) at TATS. We expect the multiple to be caused by a mid crustal discontinuity beneath TATS. We found a $32 \mathrm{~km}$ Moho depth at AFFS. This is inconsistent with prior published reliable results of the AFIF station (39.0 km) [13] (see Table 2); this may be due to damage, which occurred to the AFFS station, that apparently affected the noise level of the recorded waveform data.

\subsection{Stations around the Gulf of Aqaba}

TAYS: We have been able to stack 30 receiver functions for TAYS (see the electronic supplementary Fig. S3). We observed a coherent $\mathrm{PS}_{\text {Moho }}$ arrival based on the slant stacking of the $\mathrm{PS}_{\mathrm{Moho}}$ and multiples, we estimated a Moho depth of $28.2 \pm 1.9 \mathrm{~km}$ with a $\mathrm{Vp} / \mathrm{Vs}$ of $1.72 \pm$ 0.06 for TAYS. Our grid search modeling results indicated a Moho depth of $29.5 \pm 2.4 \mathrm{~km}$ for the Moho, which is consistent with our slant stacking Moho depth.

Our results for other Gulf of Aqaba stations (ALWS, HAQS, AYUS, BDAS, JMOS, JMQS, and HITJ) are listed in Table 1 and shown in Figs. 2 and 8. In the following we briefly highlight some of the more important observations. For example, we observed a coherent multiple around 7-8 seconds regardless of distance or azimuth at station ALWS. Also, our slant stacking result shows less control over Vp/Vs than over Moho depth, which is due to the thin crust. Due to the high noise level at HAQS station, we were able to only find 11 receiver 
functions with signal to noise ratios greater than 2. We observed a Moho depth that is consistent with other Gulf of Aqaba stations. We also observed a larger delay in the Moho phase for earthquakes south-southeast of the station, possibly indicating thicker crust in that direction. The Vp/Vs value at AYUS (Table 1) is lower than that of other Gulf of Aqaba stations and could be associated with the high level of noise and limited azimuthal coverage at this station. Although our Moho depth result at JMOS is consistent with other Gulf of Aqaba stations, the Vp/Vs value is surprisingly high. This station is close in location to ALWS (Fig. 2). Both stations have high Vp/Vs values that suggest these results may be reliable. The crust at JMQS station is $36.6 \pm 1.5$ km. This station is located east of the other Gulf of Aqaba stations (Fig. 2) and the Moho depth indicates that the crust is thickening to within normal shield or platform crust. We observed a Moho depth of $36.4 \pm 1.4 \mathrm{~km}$ at HITJ. Similar to JMQS we believe the crustal thickness at HITJ has thickened to normal platform thickness values. Rodgers et al. [20] observed a crustal thickness of $36 \mathrm{~km}$ for HITJ that is consistent with our results.

\subsection{Stations along the Red Sea}

FRSS: This station is located on a small island near the eastern Red Sea coast (Fig. 2). The island marks the end point for the deep seismic refraction profile that was interpreted by Mooney et al. [11]. We found 24 receiver functions corresponding to events east, southeast, and northwest of the station (Fig. 6a, b). In our slant stacking we did not observe PS $_{\text {Moho }}$ and Moho multiples crossing. Because of that, we stacked the data for $\mathrm{PS}_{\mathrm{Moho}}$ and PpSs+PsPs phases with weighing of 0.8 and 0.2, respectively. Our slant stacking result is shown in Fig. 6c. We found a Moho depth of $14 \pm 1 \mathrm{~km}$ and a $\mathrm{Vp} / \mathrm{Vs}$ of $1.7 \pm 0.09$ for this station. We have also used the grid search technique to model the receiver function stack for this station. Our grid search results are 
shown in Fig. 6d, e. We found the best model to consist of 4 layers with a Moho depth of $11 \mathrm{~km}$ and an error of $1.2 \mathrm{~km}$. We observed a coherent arrival at 11 seconds, labeled Pxs in Fig. 6b, that can be associated with a velocity discontinuity at approximately $100 \mathrm{~km}$, if this phase is not a multiple.

Results for other Red Sea stations (YNBS and LTHS) are listed in Table 1 and shown in Figs. 2 and 8 . In the following we briefly highlighted the more important results. Trying to estimate the Moho depth for YNBS station, we encountered some problems with both the slant stacking and grid search techniques. In our slant stacking we did not observe PS $_{\text {Moho }}$ and Moho multiples crossing. Because of that, we stacked the data for $\mathrm{PS}_{\mathrm{Moho}}$ and PpSs+PsPs phases with weighting of 0.8 and 0.2 , respectively. We estimated the Moho depth and the $\mathrm{Vp} / \mathrm{Vs}$ to be $31.6 \pm$ $3.42 \mathrm{~km}$ and $1.7 \pm 0.082$, respectively. Using our grid search technique we found the optimal model to consist of 5 layers with a Moho depth of $28 \mathrm{~km}$. Although we encountered problems in both techniques, their Moho depth values are consistent. The two stations (YNBS and LTHS) are located in the same tectonic environment. Similar to YNBS we did not observe PS $_{\text {Moho }}$ and Moho multiples crossing for LTHS and we used similar weights for the slant stacking. We estimated the Moho depth for LTHS to be $22.2 \pm 1.9 \mathrm{~km}$ with a Vp/Vs of $1.74 \pm 0.07$. Our results for LTHS are consistent with the station YNBS (see above) in that the crust is thinner along the Red Sea compared to the Arabian Shield. The significant variations $(\sim 10 \mathrm{~km})$ in crustal thickness values at stations YNBS and LTHS receiver functions may be the result of lateral variations along the Red Sea, and the fact that they are located in terranes of oceanic affinity where the crust-mantle transition have been observed to be gradual [36].

\subsection{Stations within the Arabian platform}


HASS: This station is located in the eastern part of the Arabian platform close to the Arabian/Persian Gulf. We observed a near direct P arrival (a secondary arrival that was shifted 0.75 second from the main peak), which we believe can be associated to a relatively thick ( $~ 8$ km) sedimentary layer over the metamorphic basement (see the electronic supplementary Fig. S4). Compared to other stations used in this study, HASS receiver functions are complicated. For example, although the Moho phase was coherent and clear, it was longer period than the other phases. Also, later arriving crustal multiples (PpPs and PsPs+PpSs) were sometimes absent or masked by noise. Our slant stacking result for HASS indicated a $41 \pm 0.5 \mathrm{~km}$ Moho depth with $1.81 \pm 0.02 \mathrm{Vp} / \mathrm{Vs}$. Based on $\mathrm{PS}_{\text {Moho }}$ delay time, regional tectonics, and previous studies we believe that the crust should be thicker and the $\mathrm{Vp} / \mathrm{Vs}$ value we found is high. In fact when we stacked our data for different distances we came up with an average 5 second PS $_{\text {Moho }}$ delay corresponding to 45 - $50 \mathrm{~km}$ Moho depth. Although we tested our data for azimuthal and distance variations, we were not able to observe any azimuthal dependence in the receiver function waveforms. We also performed grid search modeling over a large number of model parameters (2 to 6 layers, with both $\mathrm{Vp}$ and Vp/Vs varying); we found that the best model to fit HASS waveform data consists of 4 layers of crust with a total thickness of $53 \mathrm{~km}$ (see the electronic supplementary Fig. S4). We believe that the main reasons for the complicated receiver functions could be the interference of the $\mathrm{PS}_{\mathrm{Moho}}$ phase with multiples from the sedimentary layer(s).

RUWJ: This station is located in northeast Jordan. We estimated a Moho depth of $37.2 \pm 0.8$ km for RUWJ with a Vp/Vs of $1.78 \pm 0.02$ (Fig. 7). Our observation is consistent with previous seismic and gravity results [18, 19]. Rodgers et al. [20] studied the receiver functions for RUWJ, 
however, they did not report the RUWJ results but did mention that the complexity in the crustal response is probably due to shallow structure and site effects. In our study we observed a very clear $\mathrm{PS}_{\mathrm{Moho}}$ and multiples crossing for this station. In fact we believe the station to be one of the best stations used in our slant stack. We also noticed a coherent multiple around 2 seconds, labeled Pxs (Fig. 7b), which could be due to a mid crustal discontinuity at about $13 \mathrm{~km}$ depth.

QURS: We have difficulty in slant stacking events for QURS station. We find a slightly thinner crust and lower Vp/Vs at QURS than at RUWJ. We estimated the depth to Moho at QURS to be around $32.4 \mathrm{~km}$ with Vp/Vs of 1.71. Our 2 STD bootstrap errors for the Moho depth and Vp/Vs were $\pm 4.5 \mathrm{~km}$ and \pm 0.1 , respectively.

We have also included the results of Sandvol et al. [13, 19] and Al-Lazki et al [17] in our study (Table 2). All the Moho depth results are shown in Fig. 8 with the estimated errors. In general, the average crustal thickness for the shield stations is $39 \mathrm{~km}$. Along the escarpment in western Arabia the average Moho depth is $40 \mathrm{~km}$. The average Moho depth for the Gulf of Aqaba stations is $29 \mathrm{~km}$, while along the Red Sea coast it is about $23 \mathrm{~km}$. We observed shallower Moho for stations along the Red Sea and Gulf of Aqaba than in the shield. The change in Moho depth becomes more pronounced when we compare stations LTHS and TAIF or especially FRSS and DJNS (see Figs. 2 and 8) where a change of about $25 \mathrm{~km}$ in Moho depth occurs in a distance of less than $200 \mathrm{~km}$. Towards the east we observed a slight thickening of the crust near the platform, where the Moho depth reaches about $44 \mathrm{~km}$. Our observations in the shield are consistent with previous studies of Mooney et al. [11] and Sandvol et al. [13]. In the northern part of the platform, the crust varies from 33 to $37 \mathrm{~km}$; this is less than the average crust of the shield. The observed Moho depths in Oman, which varies between 41-49 km, and HASS 
station (see Figs. 2 and 8) seem to indicate that the crust in the southern part of the platform is thicker than the northern part. We consistently observed thin crust along the Red Sea and Gulf of Aqaba coasts that increases rapidly in thickness near the escarpment, after which the crustal thickness stabilizes and increases slightly near the eastern part of the shield.

\section{Discussion and Implications}

The Moho depth values presented in Fig. 8 represent the average measurements of crustal thickness under the respective seismic stations. To better visualize the results in a simple way we have contoured our observations. In general, there is not a unique set of contour lines for a given set of measurements, especially when the input data are sparse and/or not evenly distributed. In order to create a more objective Moho map we employed the kriging technique [37] and the contour command available in ARC/INFO tools. Kriging our observations had a number of problems: the software cell size limitation's forced us to use a coarser cell size where the data are sparse; also there were difficulties in quantifying some of the parameters that are significant for contouring, for example, the tectonic history of the region. Since our observations are more dense in the Arabian shield and along the margins of the Red Sea and the Gulf of Aqaba, we limited our contouring only to these regions. To limit the kriging process from extending beyond the Red Sea, we assumed a $5 \mathrm{~km}$ Moho depth along the mid-ocean ridge in the central part of the Red Sea. Finally, we contoured the kriging output based on a $10 \mathrm{~km}$ interval. We also contoured our results manually by visual inspection taking into account the topography, bathymetry, and the tectonic history of the region. To minimize contouring uncertainties in the hand drawn process we did not require a specific contouring interval or continuous contour lines and, thus, most of the contour lines stop where there are no data. 
Our contouring results are shown in Fig. 9. It is encouraging that contours based on the kriging technique are similar to those based on the visual, hand drawn process. However, the 40 km contour line based on the kriging technique deviates toward the interior of the shield because many Moho values are close to $40 \mathrm{~km}$ within the shield. The contour lines of both techniques show the dramatic change in crustal thickness between the topographic escarpment along the western margin of the Arabian shield and the shorelines of the Red Sea. On average the distance between the escarpment and the shorelines is approximately $65 \mathrm{~km}$. Based on the contour map and the results in Fig. 8, the Moho depth in the shield is relatively stable, and ranges between 35 and $45 \mathrm{~km}$. The average Moho depth in the Arabian shield is $39 \mathrm{~km}$.

Our results in the Arabian shield provide an excellent opportunity to compare Moho depth determinations for a relatively young, late Proterozoic shield to other determinations for other shield regions on earth. After a careful search of the available literature we identified nine Proterozoic and Archean shield regions that include reasonably well-determined Moho depths (Table 3). Most of these determinations are based on relatively recent research results using receiver functions. However, a few determinations are based on high-quality deep seismic (refraction) soundings (DSS). Crustal receiver function results can be considered an average measurement of Moho depth in proximity of a seismic station $(\sim 15 \mathrm{~km})$, which is an advantage over the DSS method in which the Moho depth is more of an average over a relatively long path (> $150 \mathrm{~km}$ ). When the average Moho depth (column 5 in Table 3) is not provided by the author(s), we averaged all shield receiver function results, and for the DSS results we averaged the minimum and maximum Moho depth along the seismic line.

We found that the average crustal thickness for all the studies in Table 3 is $39 \mathrm{~km}$, while the average for Proterozoic shields is $40 \mathrm{~km}$, and the average for Archean shields is $38 \mathrm{~km}$. The Archean is slightly less thick than the Proterozoic crust. The standard deviation for all the 
studies is $3.41 \mathrm{~km}$, while the standard deviations are $3.42 \mathrm{~km}$ and $3.45 \mathrm{~km}$ for the Archean and Proterozoic shields, respectively. In general, we found that the crustal thickness of a Proterozoic shield to vary between 33 and $44 \mathrm{~km}$, while in Archean shields it varies between 32 and $47 \mathrm{~km}$. Fig.10 is a plot of the average Moho depth versus average age for all the studies presented in Table 3. Overall we do not observe a significant trend in the Moho depth with the average age of Precambrian crusts. That is, there is no significant difference between Proterozoic and Archean crustal thickness, and the variations we listed above for Moho depths lie within the margin of errors for these determinations. With the exception of young orogens, several authors have proposed general ascending relationship between crustal thickness and age (e.g. [38, 39]); however, other authors (e.g. [40,41]) argued for thicker Proterozoic crusts in comparison to Archean shields. The results presented in Fig. 10 are in contrast to the published results that suggest a relationship between the crustal thickness and the age of a given Precambrian crust. It appears that the average thickness of an Archean crust has not changed much relative to a Proterozoic crust, with an average thickness of about $40 \mathrm{~km}$. This suggests that if Archean crust is subjected to deformation and/or magmatic episodes that resulted either in a thicker or thinner crust, then subsequent crustal processes such as crustal flow (e.g. [42]) or crustal underplating (e.g. [43]), or crustal delamination (e.g. [42]) tend to stabilize the crustal thickness back to about $40 \mathrm{~km}$. Clearly more observations, especially in Proterozoic shields, are needed to draw any more firm conclusions regarding Precambrian crustal thickness.

In addition to contouring our Moho depth observations, we have projected our Moho depths along a cross section (Fig. 11a) running from the Red Sea ridge to the Arabian/Persian Gulf. We have selected the location of this cross section to span a relatively dense distribution of observations. The cross section (Fig. 11b ) shows a dramatic increase in Moho depth from near the Red Sea coastline to the shield escarpment, after which the change in depth stabilizes and 
little undulation in the Moho depth can be seen. In particular, Fig. 11c shows the dramatic reduction with Ps-P times for stations located to the west of the escarpment. This dramatic change in crustal thickness occurs over a relatively short distance; for example, the Moho depth at station LTHS along the Red Sea coast (see Figs. 2 and 8) is about $22 \mathrm{~km}$, but at a distance of about $50 \mathrm{~km}$ to the east of this station the Moho depth increases to over $40 \mathrm{~km}$.

From the cross section of Fig. 11, the distance from the Red Sea ridge to the escarpment is about $250 \mathrm{~km}$. The relatively short distance over which the crust changes from oceanic to a typical continental crustal thickness is an important observation. This led us to contrast our observation with a typical Atlantic continental margin. Fig. 12 clearly shows that the transition from oceanic to continental crust along a typical western Atlantic margin is about $450 \mathrm{~km}$, compared with the observed $250 \mathrm{~km}$ along the Red Sea. This suggests that the Red Sea margin is fundamentally different than the Atlantic passive margin. Furthermore, it is possible that the observed abruptness of the Red Sea margin is an inherent feature in the rifting process and that over considerable geologic time the abrupt margin evolves into an extended margin.

It is tempting to speculate that the Red Sea opening may be one of the consequences of the presence of a mega plume that extends from the core-mantle boundary into the upper mantle beneath east Africa, the Red Sea, and the western portion of the Arabian plate [45, 46]. It is possible that this mega plume may have rivaled those that drove the break up of Gondwanaland and Pangea. Based on surface geologic observations and widespread volcanic activity [8] it appears that this plume has affected the lithospheric structure over a large distance ( $>4000 \mathrm{~km})$ in east Africa and western Arabia, and may have resulted in a considerable thinning of the mantle part of the lithosphere. This is partially documented in western Arabia based on the recent tomographic results of high attenuation and low velocity uppermost mantle [7, 48, 49]. Moreover, the site where the Red Sea sea-floor spreading occurred was a Proterozoic suture and 
a zone of weakness throughout the lithosphere connecting the proto-Arabian plate and the African plate [49, 50]. The above observations combined may explain the relatively abrupt breakup of the Arabian plate and the anomalous nature of the Red Sea margin.

\section{Acknowledgements}

The authors would like to thank King Abdulaziz City for Science and Technology (KACST) for providing us with the digital recordings of the Saudi National Seismic Network and providing a scholarship for the first author. We would like also to thank Lawrence Livermore National Laboratory for providing us with the digital data from stations RUWJ and

HITJ. We thank Robert Kay for useful discussions, and C. Sandvol, C. Brindisi, F. Gomez, and S. Gallow for their help in GIS and computer questions. We also thank R. Mellors and A. Rodgers for their careful review of this manuscript. This research is partially supported by the National Science Foundation grants EAR - 9804780 and EAR - 0106238 to Cornell University. 


\section{References}

[1] W.R. Greenwood, R.E., Anderson, R.J. Fleck, R.J. Roberts, Precambrian geologic history and plate tectonics evolution of the Arabian Shield, Saudi Arabia, Dir. Gen. Miner. Resour. Bull. (1980) 24-34.

[2] J.R. Cochran, F. Martinez, Structure and tectonics of the northern Red Sea: Catching a continental margin between rifting and drifting, Tectonophysics 150 (1988) 1-32.

[3] R.W. Powers, L.F. Ramirez, C. P. Redmond, E.L. Elberg, Geology of the Arabian Peninsula: Sedimentary geology of Saudi Arabia, U.S. Geol. Surv. Prof. Pap. 560-D (1966) 91-96.

[4] G. F. Brown, Tectonic map of the Arabian Peninsula, Saudi Arabian Peninsula Map Ap-2. Saudi Arabian Dir. Gen. Miner. Resour. (1972).

[5] T.A. Mokhtar, C.A. Ammon, R.B. Herrmann, A.A. Ghalib, Surface wave velocity across Arabia, Pure Appl. Geophys.158 (2001) 1425-144.

[6] M.J. Makris, R. Rhim, Shear-controlled evolution of the Red Sea: pull-apart model, Tectonophysics 198 (1991) 441-466.

[7] K. Al-Damegh, E. Sandvol, A. Al-Lazki, M. Barazangi, Regional seismic wave propagation ( $\mathrm{Lg}$ and $\mathrm{Sn}$ ) and Pn attenuation in the Arabian plate and surrounding regions, Geophys. J. Int. 157 (2004) 775-795.

[8] V.E. Camp, M.J. Roobol, Upwelling asthenosphere beneath western Arabia and its regional implications, J. Geophys. Res. 97 (1992) 15255-15271.

[9] Z. Garfunkel, Internal structure of the Dead Sea leaky transform (rift) in relation to plate kinematics, Tectonophysics 80 (1981) 81-108.

[10] D. Seber, M. Vallve, E. Sandvol, D. Steer, M. Barazangi, Middle East tectonics: Applications of geographic information system (GIS), GSA Today 7 (1997) 1-6.

[11] W.D. Mooney, M.E. Gettings, H.R. Blank, J.H. Healy, Saudi Arabian seismic-refraction profile: A traveltime interpretation of crustal and upper mantle structure, Tectonophysics 111 (1985) 173-246.

[12] M. Gettings, H. Blank, W. Mooney, J. Healey, Crustal structure in southwestern Saudi Arabia, J. Geophys. Res. 91 (1986) 6491-6512.

[13] E. Sandvol, D. Seber, M. Barazangi, F. Vernon, R. Mellors, A. Al-Amri, Lithospheric seismic velocity discontinuities beneath the Arabian Shield, Geophys. Res. Lett. 25 (1998a) 2873-2876. 
[14] M.R. Kumar, D. S. Ramesh, J. Saul, D. Sarkar, R. Kind, Crustal Structure and upper mantle stratigraphy of the Arabian shield, Geophs. Res. Lett. 29 (2002) 1-4.

[15] A. M. Al-Amri, The crustal and upper-mantle structure of the interior Arabian platform, Geophys. J. Int. 136 (1999) 421-430.

[16] A. M. Al-Amri, A. A. Gharib, Lithospheric seismic structure of the eastern region of the Arabian Peninsula, J. Geody. 29 (2000) 125-139.

[17] A.I. Al-Lazki, D. Seber, E. Sandvol, M.Barazangi, A crustal transect across the Oman mountains of the eastern margin of Arabia, GeoArabia 7 (2002) 47-78.

[18] Z.H. El-Isa, J. Mechie, J. Makris, R. Rihm, A crustal structure study of Jordan derived from seismic refraction data, Tectonophysics 138 (1987) 235-253.

[19] E. Sandvol, D. Seber, A. Calvert, M. Barazangi, Grid search modeling of receiver functions: Implications for crustal structure in the Middle East and North Africa, J. Geophys. Res. 103 (1998b) 26899-26917.

[20] A. Rodgers, D. Harris, S. Ruppert, J.P. Lewis, J. O'Boyle, M. Pasyanos, A.F. Abdallah, T. Al-Yazjeen, A. Al-Gazo, A broadband seismic deployment in Jordan, Seismol. Res. Lett. 74 (2003) 374-381.

[21] E. Zor, E. Sandvol, C. Gürbüz, N. Türkelli, D. Seber, M Barazangi, The crustal structure of the East Anatolian plateau (Turkey) from receiver functions, Geophys. Res. Lett. 30 (2003) 8044 doi:10.1029/2003GL018192.

[22] D. Seber, B. Mitchell, Attenuation of surface waves across the Arabian Peninsula, Tectonophysics 204 (1992) 137-150.

[23] T.A. Mokhtar, Phase velocity of the Arabian Platform and the surface waves attenuation's characteristics by waveform modeling, Journal of King Abdul Aziz University, Earth Sci. 8 (1995) 23-45.

[24] A. Rodgers, W.R. Walter, R.J. Mellors, A.M. Al-Amri, Y Zhang, Lithospheric structure of the Arabian Shield and Platform from complete regional waveform modeling and surface wave group velocities, Geophys. J. Int. 138 (1999) 871-878.

[25] E. Debayle, J. Leveque, M. Cara, Seismic evidence for a deeply rooted low-velocity anomaly in the upper mantle beneath the northeastern Afro/Arabian continent, Earth Planet. Sci. Lett. 193 (2001) 423-436.

[26] M.H. Benoit, A.A. Nyblade, J.C. VanDecar, H. Gurrola, Upper mantle P wave velocity structure and transition zone thickness beneath the Arabian Shield, Geophys. Res. Lett. 30 (2003) 1-4. 
[27] A. Daradich, J.X. Mitrovica, R. N. Pysklywec, S.D. Willett, A.M. Forte, Mantle flow, dynamic topography, and rift-flank uplift of Arabia, Geological Society of America 31 (2003) 901-904.

[28] S. M. Al-Amri, A. M. Al-Amri, Configuration of the seismographic network in Saudi Arabia, Seismol. Res. Let. 70 (1999) 322-330.

[29] L.J. Burdick, C.J. Langston, Modeling crustal structure through the use of converted phases in teleseismic body-wave forms, Bull. Seismol. Soc. 67 (1977) 677-691.

[30] C.A. Langston, Structure under Mount Rainier, Washington, inferred from teleseismic body waves, J. Geophys. Res. 84 (1979) 4749-4762.

[31] J.P. Ligorria, C.J. Ammon, Iterative deconvolution and receiver-function estimation, Bull. Geol. Soc. Am. 89 (1999) 1395-1400.

[32] I. Zhu, H. Kanamori, Moho depth variation in southern California from teleseismic receiver functions, J. Geophys. Res. 105 (2000) 2969-2980.

[33] B. Kennett, Seismic wave propagation in stratified media, Cambridge Univ. Press, New York (1984).

[34] B. Tichelaar, L. Ruff, How good are our best models? Jackknifing, bootstrapping, and earthquake depth, Eos Trans. AGU 70 (1989) 605-606.

[35] B. Efron, R. Tibshirani, Statistical analysis in the computer age, Science 253 (1991) 390395.

[36] J. Julia, C. Ammon, R. Herrmann, Lithospheric structure of the Arabian Shield from the joint inversion of receiver functions and surface-wave group velocities, Tectonophysics 371 (2003) 1-21.

[37] Isaaks, Srivastava, An Introduction to Applied Geostatistics, Oxford University Press (1989).

[38] R. Meissner, The Continental Crust: A Geophysical Approach, Academic Press, San Diego, CA (1986).

[39] R. Meissner, T. Wever, Continental crustal structure, in: D.E. James (Ed.), The Encyclopedia of Solid Earth Geophysics, Van Nostrand Reinhold, New York (1989), 7589.

[40] R. Durrheim, W. Mooney, Archean and Proterozoic crustal evolution: Evidence from crustal seismology, Geology 19 (1991) 606-609.

[41] R. Durrheim, W. Mooney, Evolution of the Precambrian Lithosphere: seismological and geochemical constraints, J. Geophys. Res. 99 (1994) 15359-15374. 
[42] M. Clark, L. Royden, Topographic ooze: Building the eastern margin of Tibet by lower crustal flow, Geology 28 (2000) 703-706.

[43] K.D. Nelson, A unified view of craton evolution motivated by recent deep seismic reflection and refraction results, Geophys. J. Int. 105 (1991) 25-35.

[44] J. Ritsema, H.J. van Heijst, Complex shear wave velocity structure imaged beneath Africa and Iceland, Science, 286 (1999) 1925-1928.

[45] B. Romanowicz, Y. Gung, Superplumes from the core-mantle boundary to the lithosphere: Implications for heat flux, Science 296 (2002) 513-516.

[46] A.A. Nyblade, T.J. Owens, H. Gurrola, J. Ritsema, C.A. Langston, Seismic evidence for a deep upper mantle thermal anomaly beneath east Africa, Geology 28 (2000) 599-602.

[47] E. Sandvol, K. AL-Damegh, A. Calvert, D. Seber, M. Barazangi, R. Mohamad, R. Gok, N. Turkelli, C. Gurbuz, Tomographic imaging of Lg and Sn propagation in the Middle East, Pure appl. Geophys. 158 (2001) 1121-1163.

[48] A.I. Al-Lazki, E. Sandvol, D. Seber, M. Barazangi, N. Turkelli, R. Mohamad, Pn tomographic imaging of mantle lid velocity and anisotropy at the junction of the Arabian, Eurasian, and African plates, Geophys. J. Int. 158 (2004) 1024-1040.

[49] M. Garson, M. Krs, Geophysical and geological evidence of the relationship of Red Sea transverse tectonics to ancient fractures, Bull. Geol. Soc. Am. 87 (1976) 169-181.

[50] T.H. Dixon, R.J. Stern, I.M. Hussein, Control of Red Sea rift geometry by Precambrian structures, Tectonics 6 (1987) 551-571.

[51] C.G. Bank, M.G. Bostock, R.M. Ellis, J.F. Cassidy, A reconnaissance teleseismic study of the upper mantle and transition zone beneath the Archean Slave craton in NW Canada, Tectonophysics 319 (2000) 151-166.

[52] F. Darbyshire, Crustal structure across the Canadian High Arctic region from teleseismic receiver function analysis, Geophys. J. Int. 152 (2003) 372-391.

[53] G.F. Viejo, R.W. Clowes, Lithospheric structure beneath the Archaean Slave province and Proterozoic Wopmay orogen, northwestern Canada, from a LITHOPROBE refraction/wide-angle reflection survey, Geophys. J. Int. 153 (2003) 1-19.

[54] T. Dahl-Jensen, B. Larsen, I. Woelbern, T. Bach, W. Hanka, R. Kind, S. Gregersen, K. Mosegaard, P. Voss, O. Gudmundsson, Depth to Moho in Greenland: Receiver function analysis suggests two Proterozoic blocks in Greenland, Earth Planet. Sci. Lett. 205 (2003) 379-393. 
[55] S. Chevrot, R. D. van der Hilst, The Poisson ratio of the Australian crust: Geologic and geophysical implications, Earth Planet. Sci. Lett. 183 (2000) 121-132.

[56] A.B. Reading, B.L.N. Kennett, M.C. Dentith, Seismic structure of the Yilgren Carton, Western Australia, Austr. J. Earth Sci. 50 (2003) 427-438.

[57] A.B. Reading, B.L.N. Kennett, Lithospheric structure of the Pilbara Craton, Capricorn Orogen and northern Yilgran Craton, Western Australia, from teleseismic receiver functions, Austr. J. Earth Sci. 50 (2003) 439-445.

[58] J. Stankiewicz, S. Chevrot, R. van der Hilst, M. de Wit, Crustal thickness, discontinuity depth, and upper mantle structure beneath southern Africa: Constraints from body wave conversions, Phys. Earth Planet. Inter. 130 (2003) 235-251.

[59] F. Niu, D. James, Fine structure of the lowermost crust beneath the Kaapvaal craton and its implications for crustal formation and evolution, Earth Planet. Sci. Lett. 200 (2002) 121130.

[60] V. Midzi, L. Ottemöller, Receiver function structure beneath three southern Africa seismic broadband stations, Tectonophysics, 339 (2001) 443-454.

[61] T. K. Nguuri, J. Gore, D. E. James, S. J. Webb, C. Wright, T. G. Zengeni, O. Gwavava, J. A. Snoke, and Kaapvaal Seismic Group, Crustal structure beneath southern Africa and its implications for the formation and evolution of the Kaapvaal and Zimbabwe cratons, Geophys. Res. Lett. 28 (2001) 2501-2504.

[62] G.A. Pavlenkova, K. Priestley, J. Cipar, 2D model of the crust and uppermost mantle along rift profile, Siberian craton, Tectonophysics 355 (2002) 171-186.

[63] M. Assumpucao, Crustal thickness in SE Brazilian Shield by receiver function analysis: Implications for isostatic compensation, J. Geophy. Res. 107 (2002) 1-14.

[64] M.R. Kumar, J. Saul, D. Sarkar, R. Kind, A. Shukla, Crustal structure of the Indian shield: New constraints from teleseismic receiver functions, Geophys. Res. Lett. 28 (2001) 13391342.

[65] D. Sarkar, K. Chandrakala, P. Padmavathi, A.R. Sridhar,K. Sain, Crustal velocity structure of western Dharwar Craton, South India, J. of Geodyn. 31 (2001) 227-241.

[66] A. Alinaghi, R. Kind, G. Bock, Receiver function probing of the crust and the upper mantle underneath north German basin, Scandinavia and the Baltic shields: Evidence of ancient collision zones, AGU abstract (2002).

[67] R.G. Berzin, Yu.G. Yurov, N. I. Pavlenkova, CDP and DSS data along the Uchta-Kem profile (the Baltic Shield), Tectonophysics 355 (2002) 187-200. 
[68] A. Li, K. Fischer, S. van der Lee, M.E. Wysession, Crust and upper mantle discontinuity structure beneath eastern North America, J. Geophys. Res. 7 (2002) 1-13.

[69] J.A. Grow, R.E. Sheridan, U.S. Atlantic continental Margin: A typical Atlantic-type or passive continental margin, in R.E. Sheridan, J.A. Grow (Ed.), The Atlantic Continental Margin: U.S., Geological Society of America, The Geology of North America (1988), 1-7.

[70] A.M. Goodwin, Precambrian Geology, Academic Press, New York (1991). 


\section{Figure Captions:}

Fig. 1. A simplified tectonic map showing the main tectonic features of the Arabian plate and surrounding regions.

Fig. 2. Map showing the seismic stations used in this study. In addition, the map shows stations in the region for which receiver function results were discussed in the text (squares, stars, and downward triangles). The inset shows stations along or close to the Gulf of Aqaba.

Fig. 3. A schematic ray-tracing diagram for hypothetical teleseismic plane $\mathrm{P}$ wave incident on a $40 \mathrm{~km}$ thick crust. Ps, PpPs, PpSs, and PsPs are abbreviations for the Moho phase and the following multiples that we used in this study to estimate the crustal thickness for the Arabian plate.

Fig. 4. a) A map showing the epicenters (open circles) for the earthquakes corresponding to the slant stacked receiver functions in (b). The recording station KBRS is shown by a solid triangle. b) Receiver functions corresponding to the earthquakes in (a). The two columns represent the distance $(\Delta)$ and the azimuth (AZ) in degrees for the corresponding earthquake. c) H vs Vp/Vs plot showing our estimated Moho depth $(+)$ and the bootstrap error analysis results $(\mathrm{x})$. d) The resulting waveform synthetic fit (dashed line) using the grid search technique and the observed stacked receiver functions (solid line). e) Jackknife shear velocity models obtained from resampled receiver function stacks. A dark line indicates the mean model. Thin lines indicate the maximum and minimum models. The slant stacking and grid search Moho depth estimates are almost identical.

Fig. 5. a) A map showing the epicenters (open circles) for the earthquakes used in the slant stacked receiver functions in (b). The recording station NAMS is shown by a solid triangle. b) Receiver functions corresponding to the earthquakes in (a). The two columns represent the distance $(\Delta)$ and the azimuth (AZ) in degrees for the corresponding earthquake. A clear and consistent mid-crustal discontinuity is marked by Pxs. c) $\mathrm{H}$ vs $\mathrm{Vp} / \mathrm{Vs}$ plot showing our estimated 
Moho depth (+) and the bootstrap error analysis results (x). We observed a dramatic change in crustal thickness between FRSS (Fig. 6) and NAMS.

Fig. 6. a) A map showing the epicenters (open circles) for the earthquakes used in the slant stacked receiver functions in (b). The recording station FRSS is shown by a solid triangle. b) Receiver functions corresponding to the earthquakes in (a). The two columns represent the distance $(\Delta)$ and the azimuth (AZ) in degrees for the corresponding earthquake. c) H vs Vp/Vs plot showing our estimated Moho depth (+) and the bootstrap error analysis results (x). d) The resulting waveform synthetic fit (dashed line) using the grid search technique and the observed stacked receiver functions (solid line). e) Jackknife shear velocity models obtained from resampled receiver function stacks. The dark line indicates the mean model and the thin lines indicate the maximum and minimum models. The crustal thickness is very thin near the eastern coast of the Red Sea.

Fig. 7. a) A map showing the epicenters (open circles) for the earthquakes used in the slant stacked receiver functions in (b). The recording station RUWJ is shown by a solid triangle. b) Receiver functions corresponding to the earthquakes in (a). The two columns represent the distance $(\Delta)$ and the azimuth (AZ) in degrees for the corresponding earthquake. We observed a mid-crustal discontinuity (probably corresponding to the base of the sedimentary layer) shown by Pxs. c) H vs Vp/Vs plot showing our estimated Moho depth (+) and the bootstrap error analysis results (x).

Fig. 8. Moho depth results with error estimates for the 36 stations shown in Fig. 2 plotted over a topography map. The thickest crust is along the Arabian shield escarpment. Thinner crust was observed along the Red Sea coast and Gulf of Aqaba. A dramatic change in Moho depth between stations along the Arabian shield escarpment and stations along the Red Sea coastline can be observed. It should be noticed that the errors presented here are based on statistical resampling methods (bootstrap) and reflect the consistency in our data. Certainly the actual total 
error in determining the absolute Moho depth by any geophysical method might exceed these numbers.

Fig. 9. Map showing our crustal thickness contour map. Stations are shown as open triangles. The contour lines based on the kriging approach are shown in gray and the hand drawn contour lines are shown in solid black. The figure shows also the outline of the Arabian shield (open small circles), the escarpment (long dashes), and the Red Sea ridge (small dashes).

Fig. 10. A plot of average Moho depth results from different shield regions (see Table 3) versus the average age of the shield. Different symbols were used for age ranges. Lines connect the minimum and maximum Moho depth and age span.

Fig. 11. Map and cross-sections showing Moho depth at stations along a profile from the Red Sea to the east coast of Arabia. a) Map showing the location of the profile. b) The cross section with vertical exaggeration. c) Stacked radial receiver functions for distances $70^{\circ}-85^{\circ}$ for the same stations shown in the cross section (b).

Fig. 12. A cross section showing the Moho profile contrasting a typical western Atlantic continental margin (modified from Grow and Sheridan [69]) to the eastern Red Sea margin (based on our results). The distance between an average continental and oceanic crust in the Red Sea is half of that in the western Atlantic margin. The dotted line is our extrapolation for the oceanic crust. 


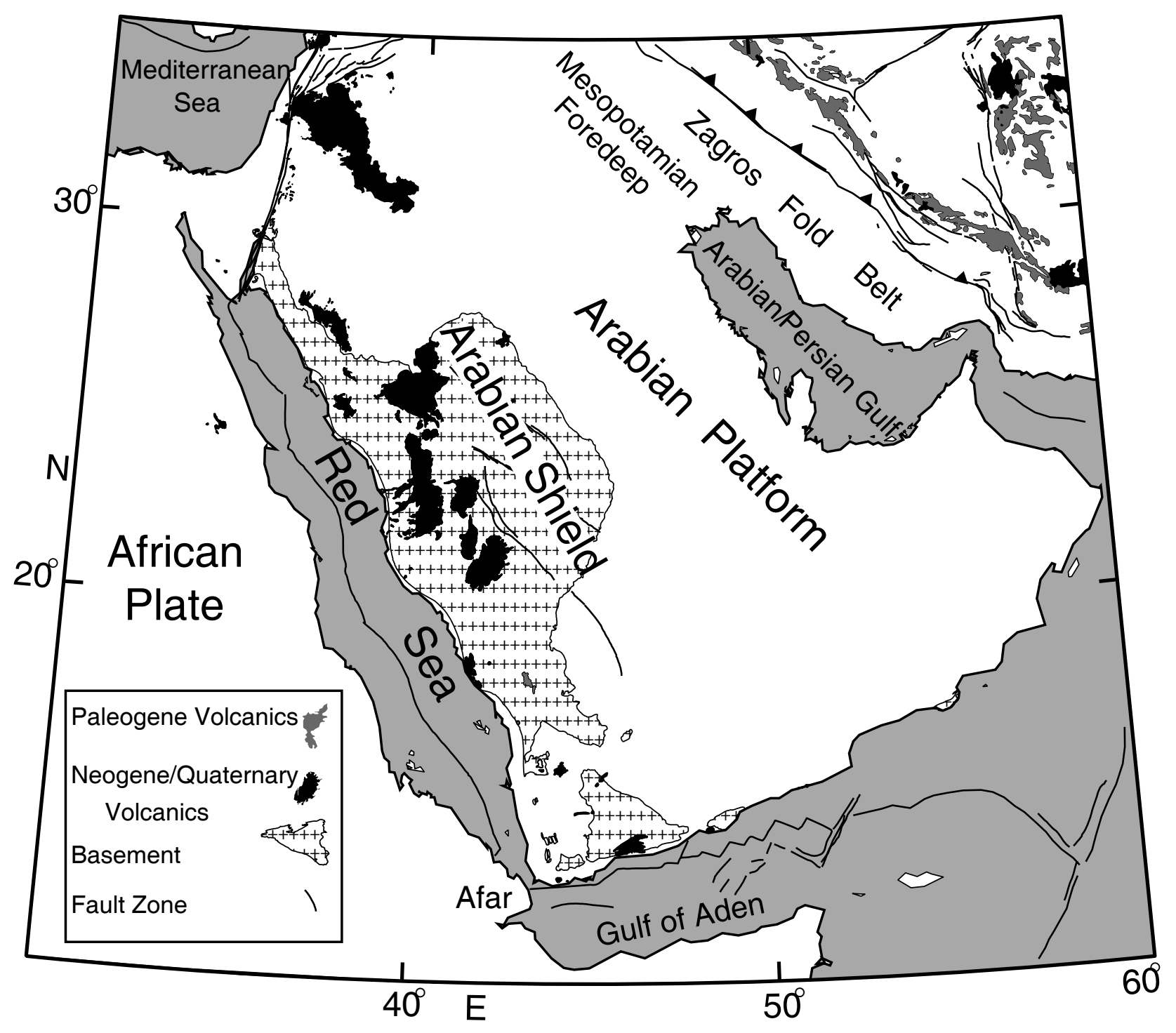

Figure 1 


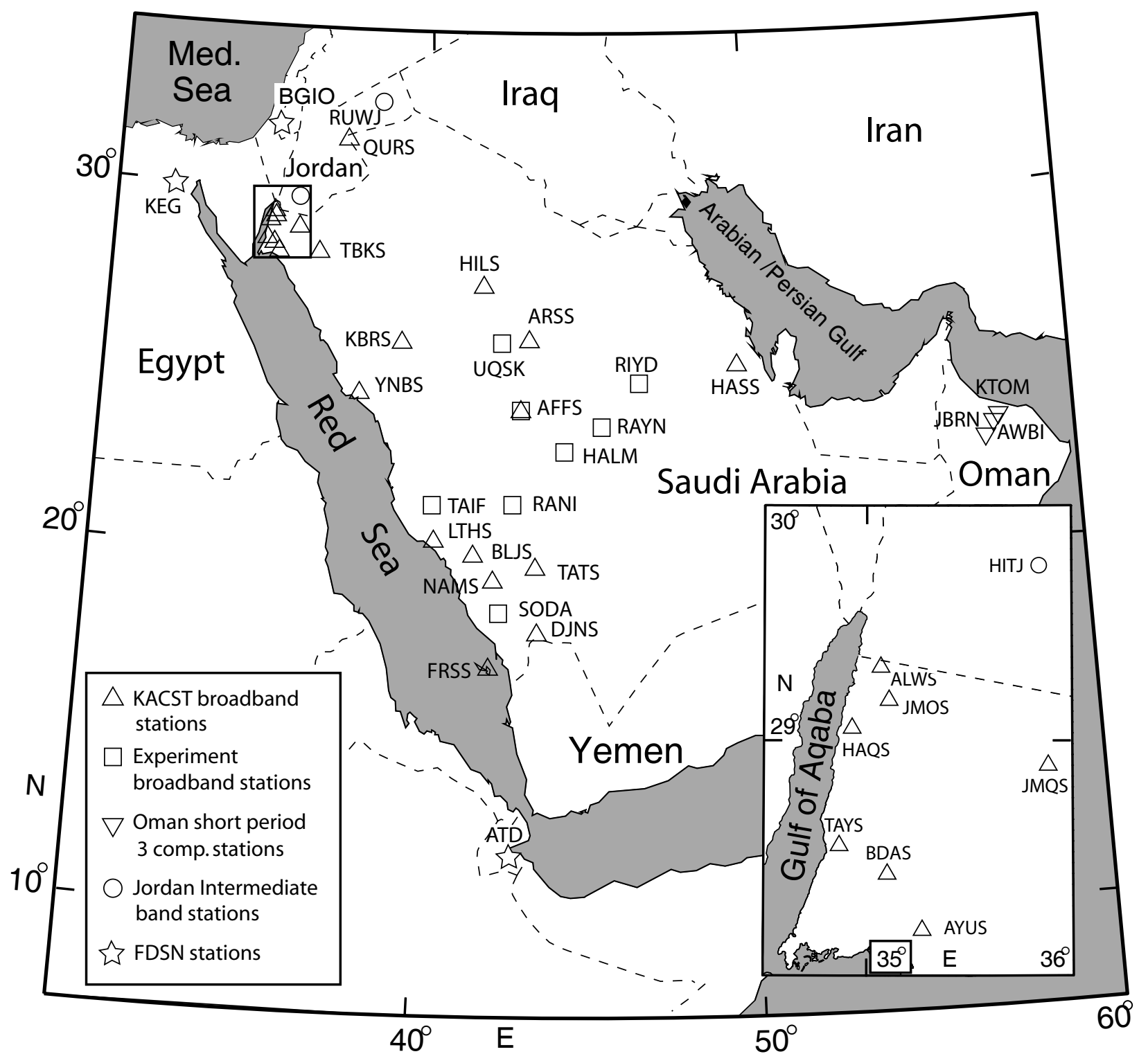

Figure 2 


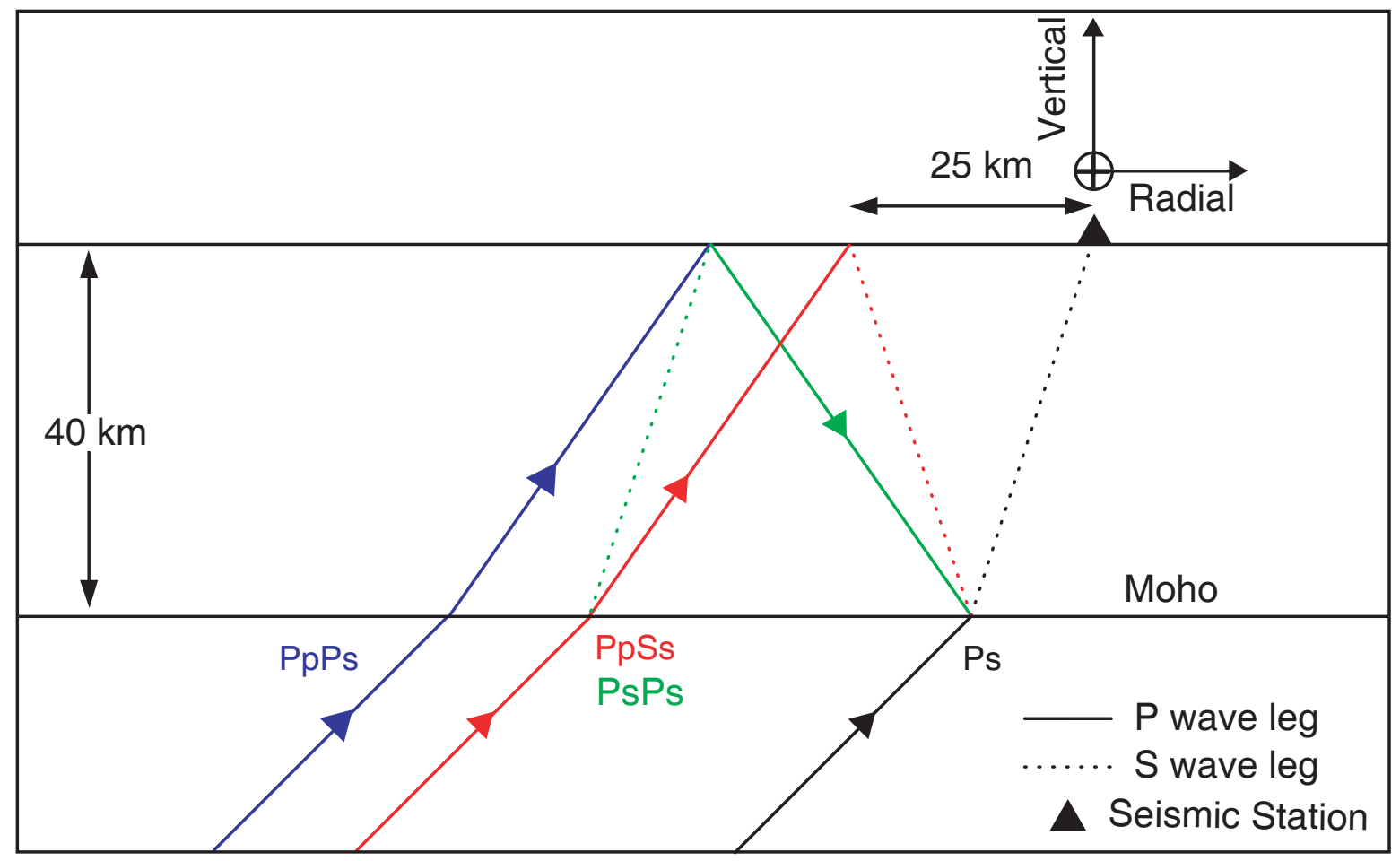

Figure 3 


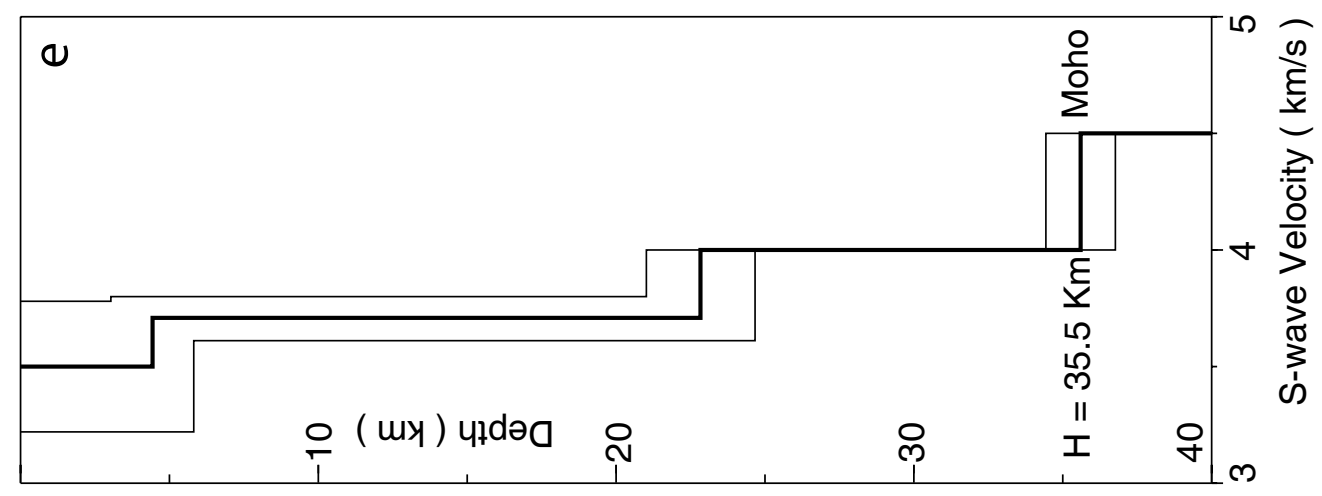

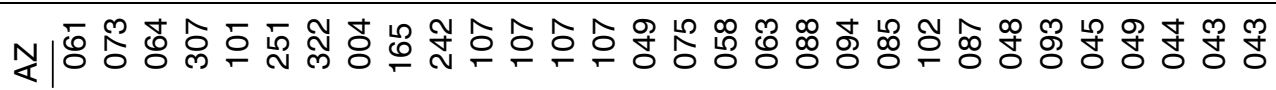

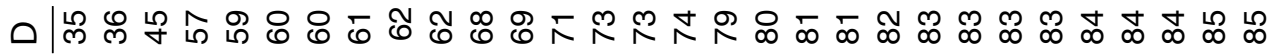
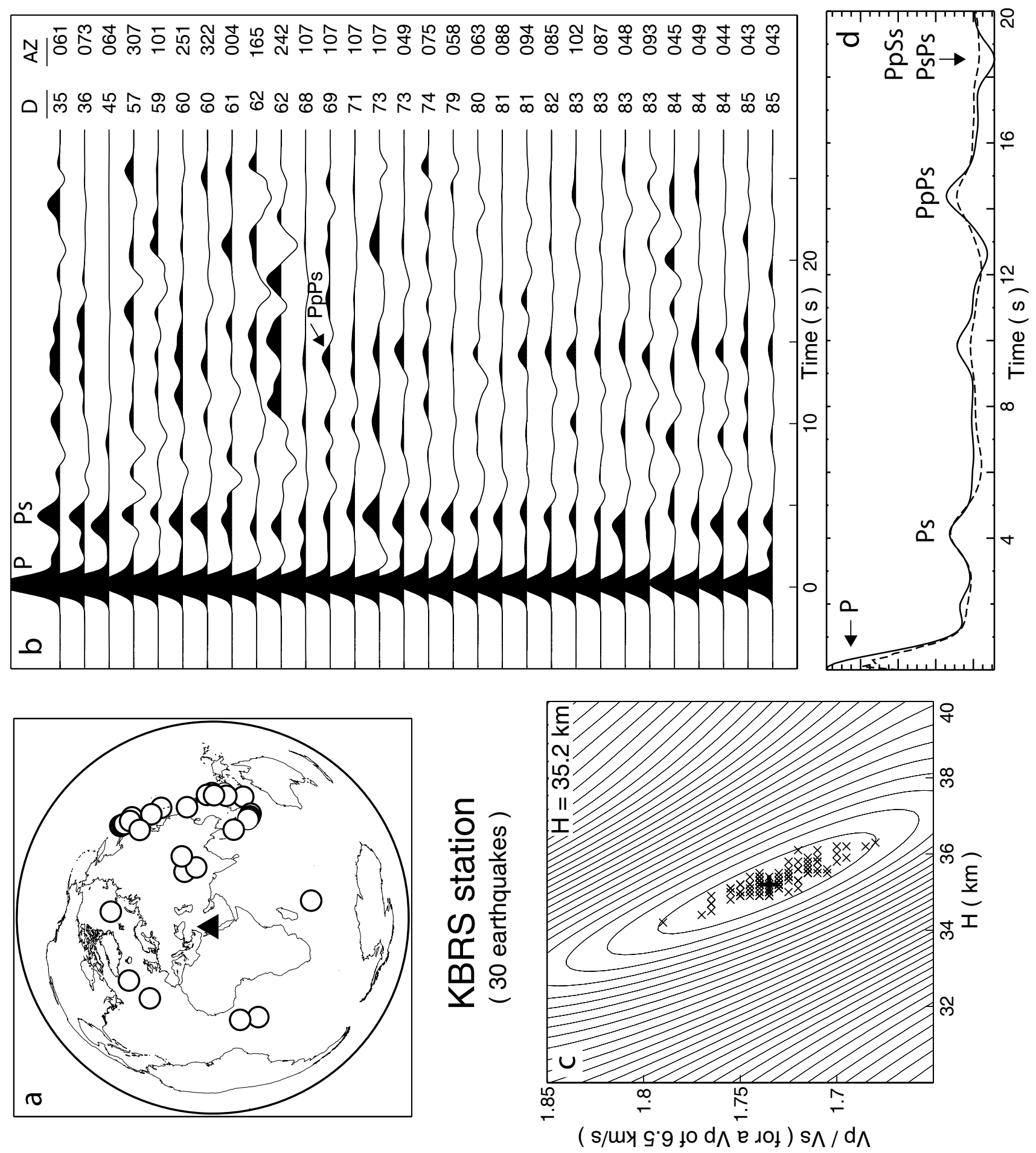

Figure 4 


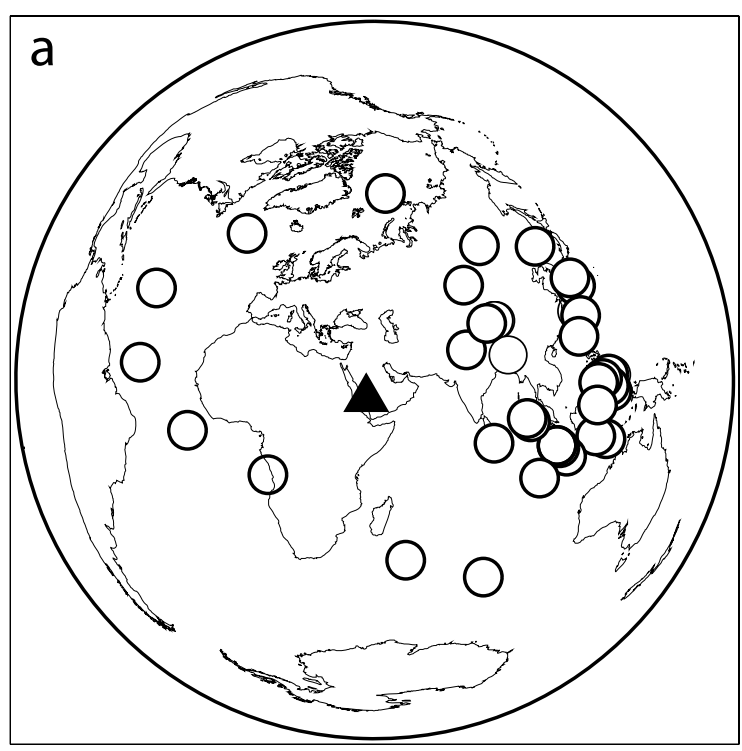

NAMS station

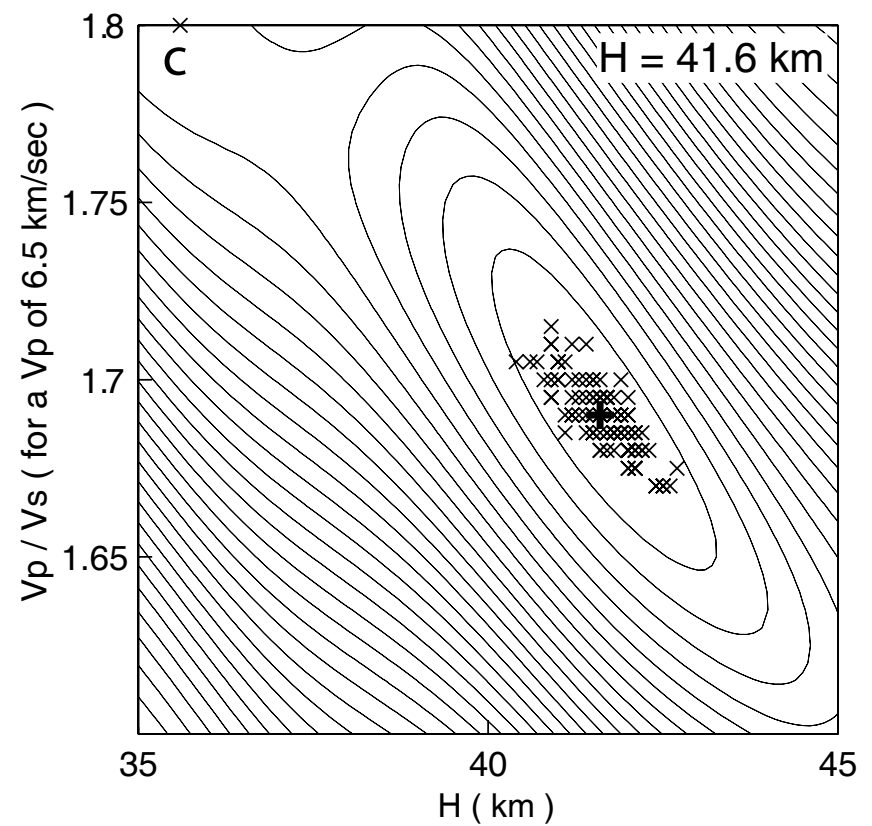

( 42 earthquakes )

b

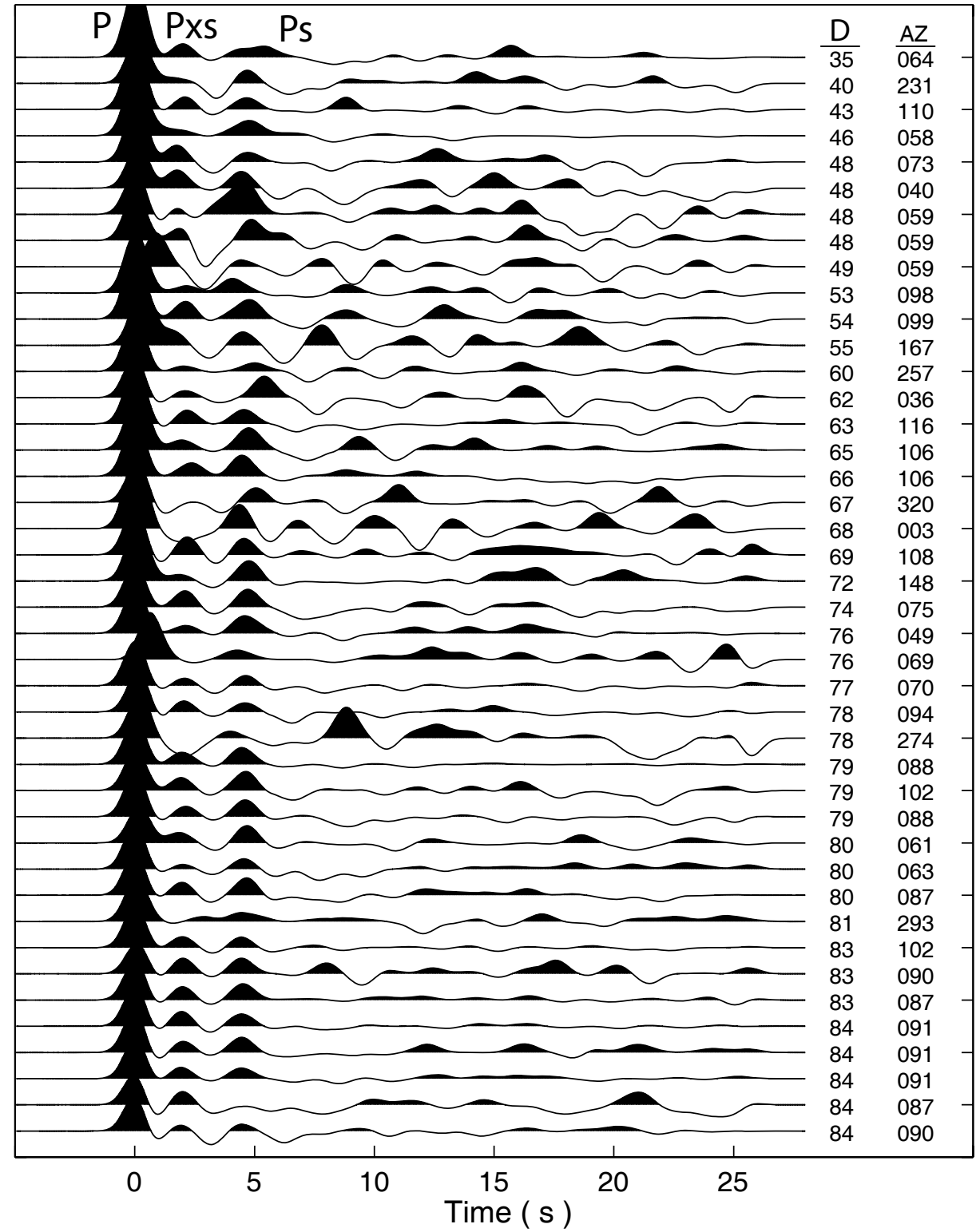

Figure 5 


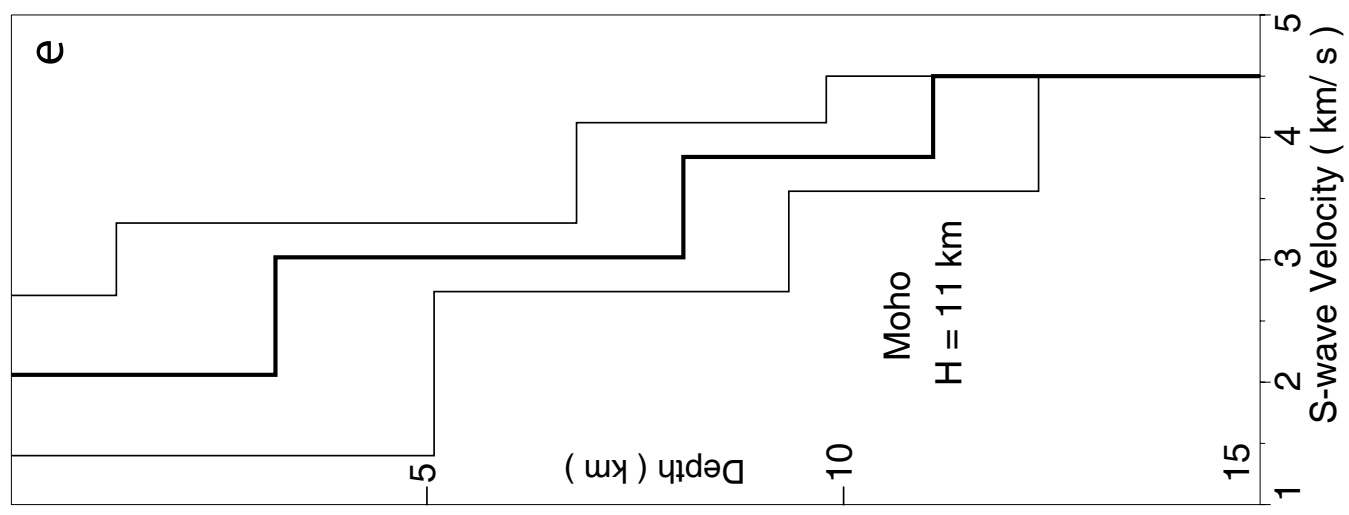

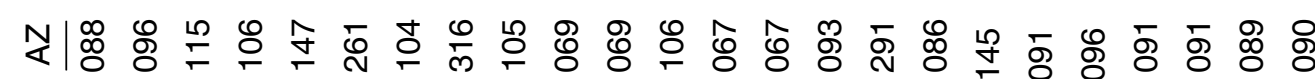

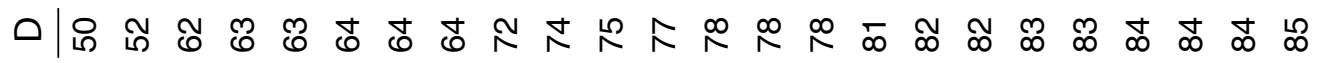
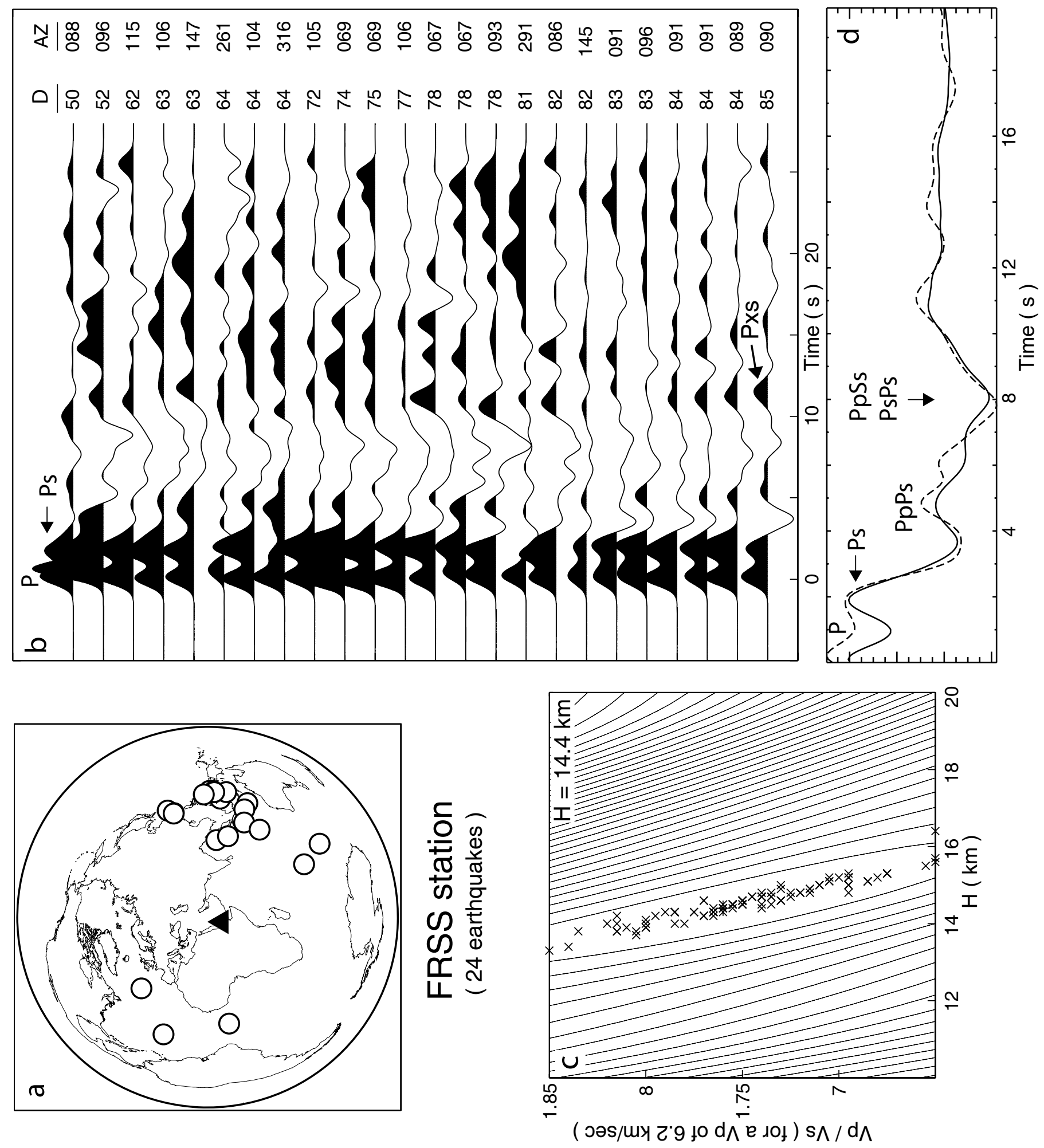

Figure 6 


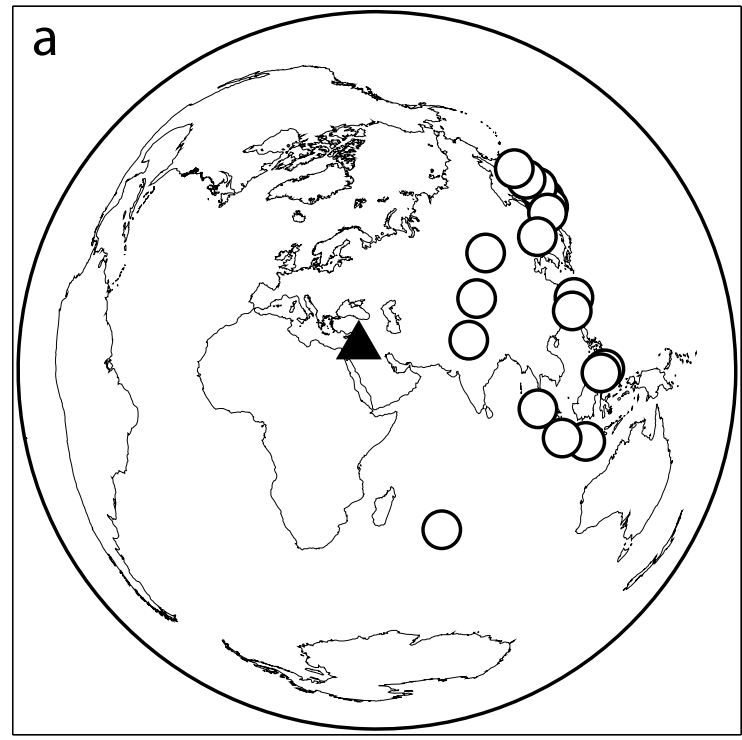

RUWJ station

( 18 earthquakes )

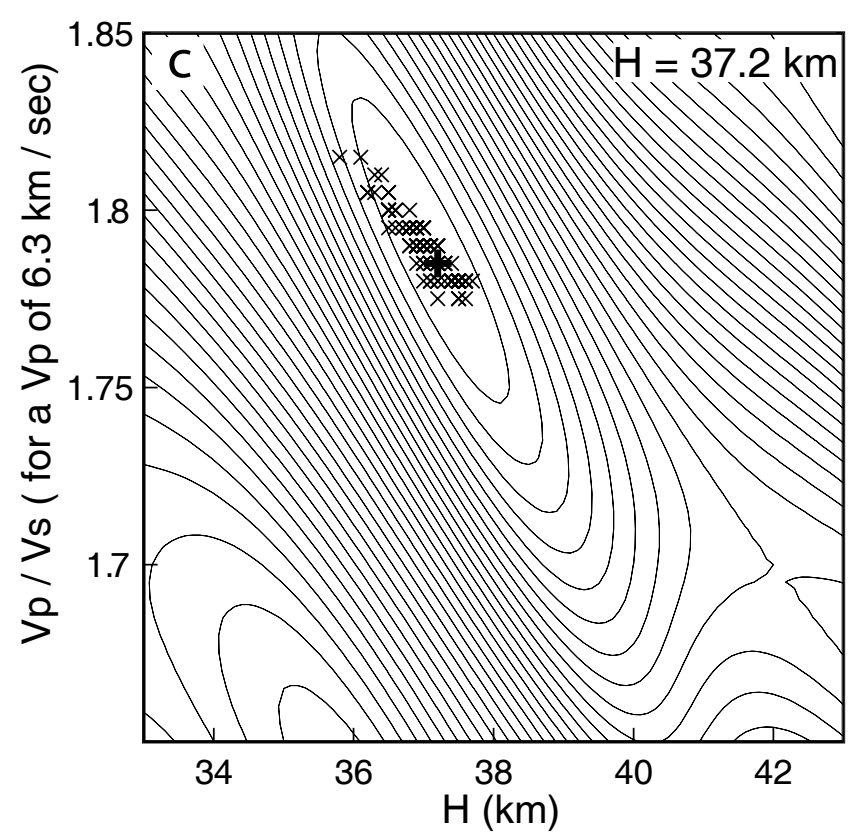

b

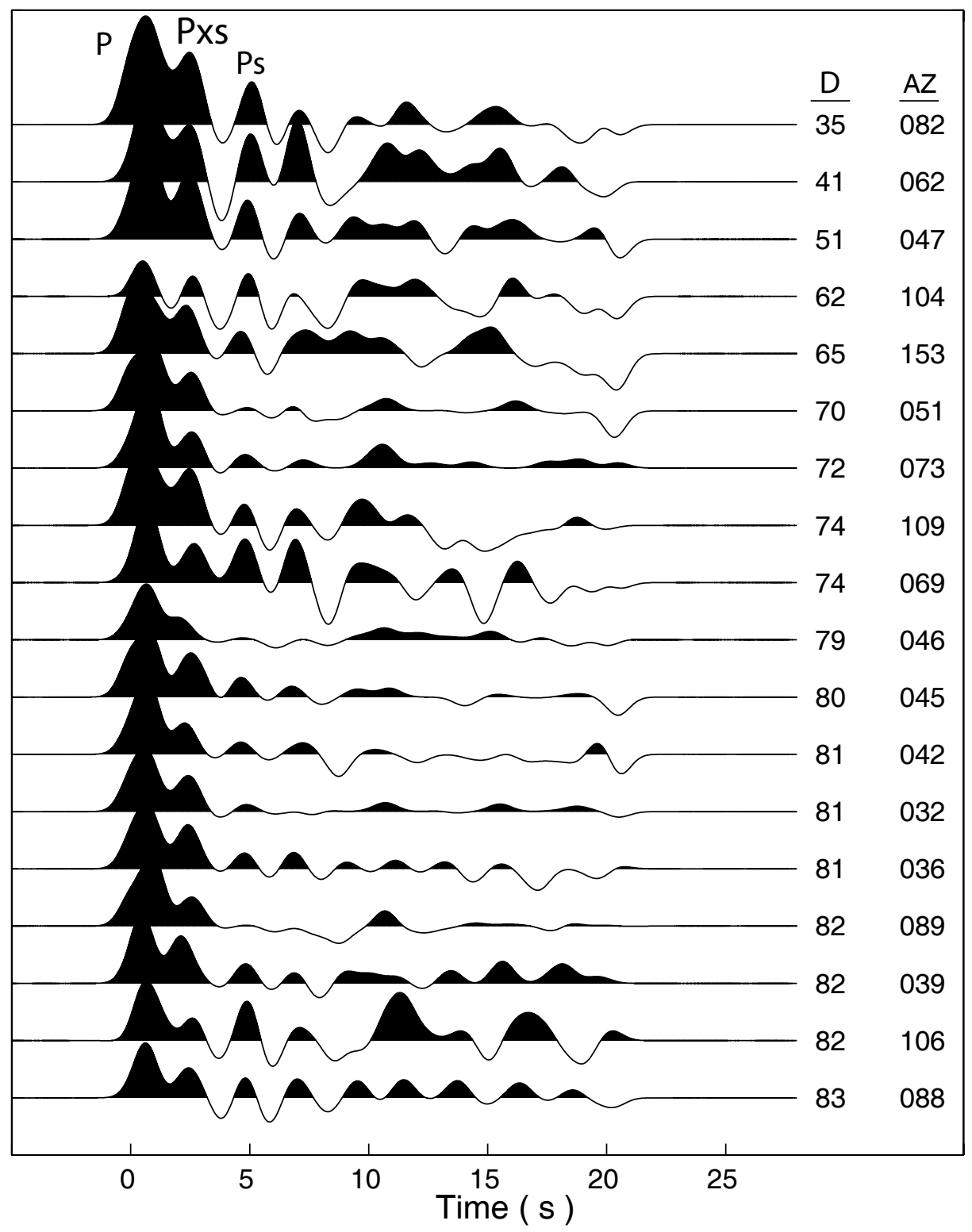

Figure 7 


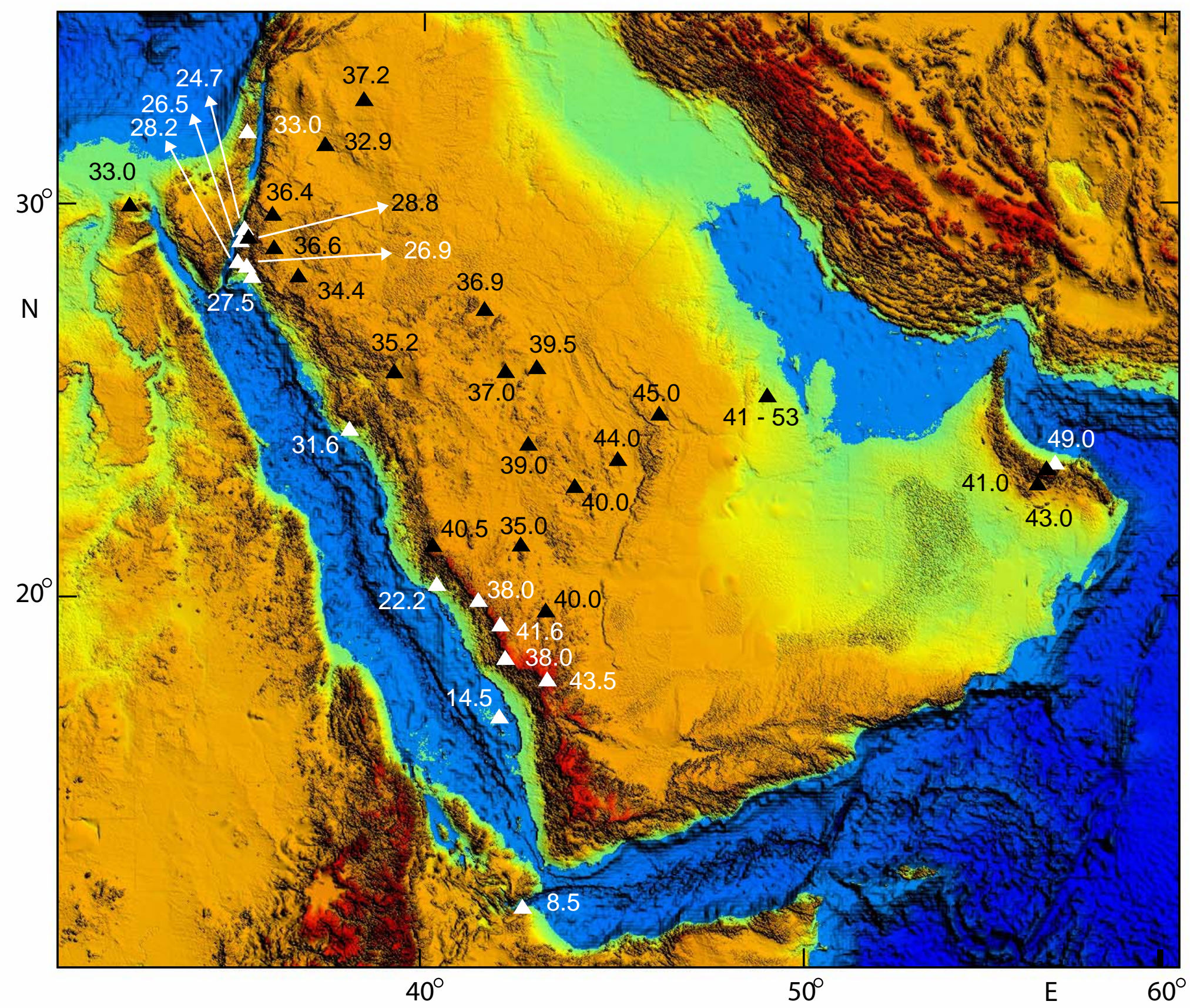




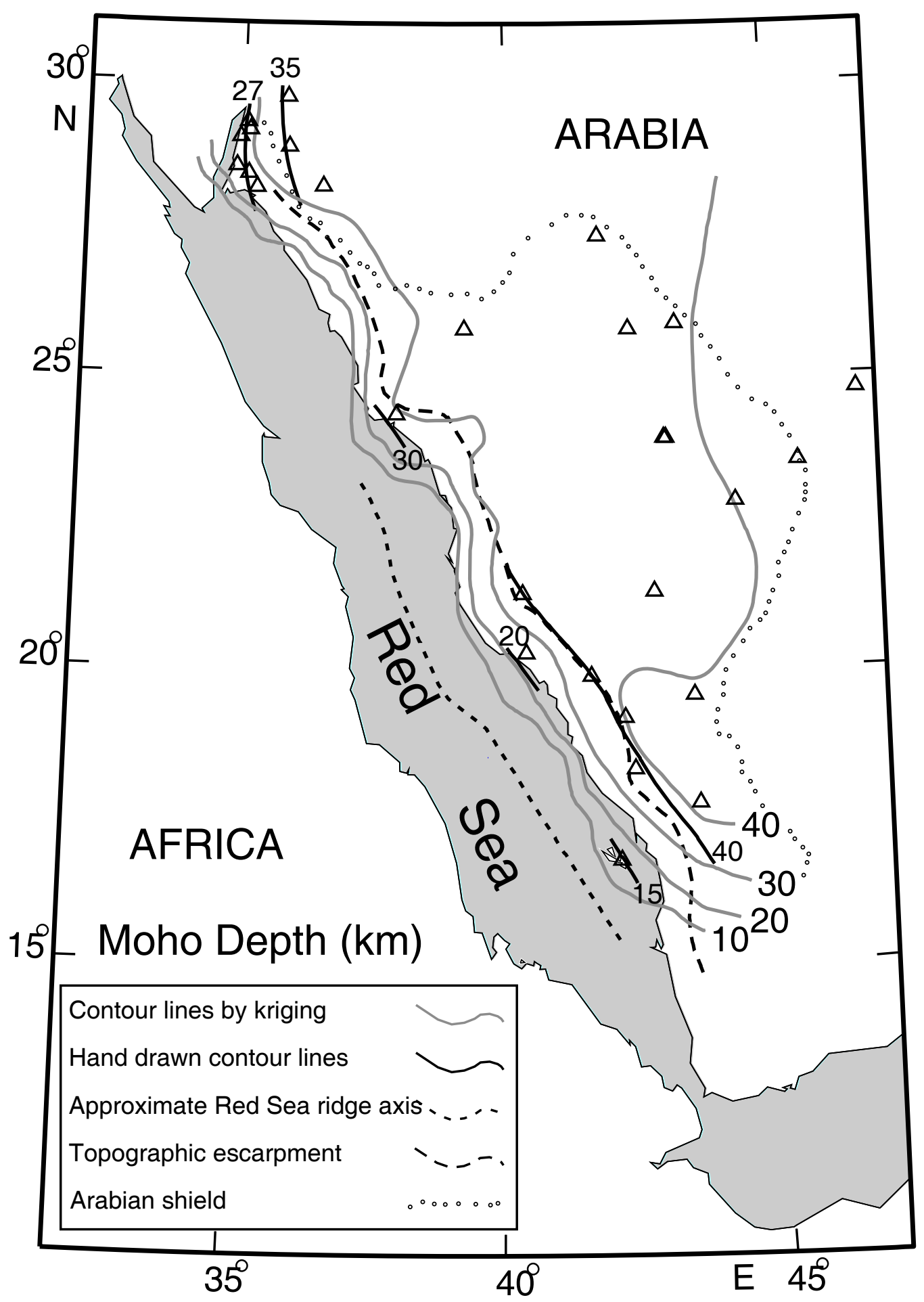

Figure 9 


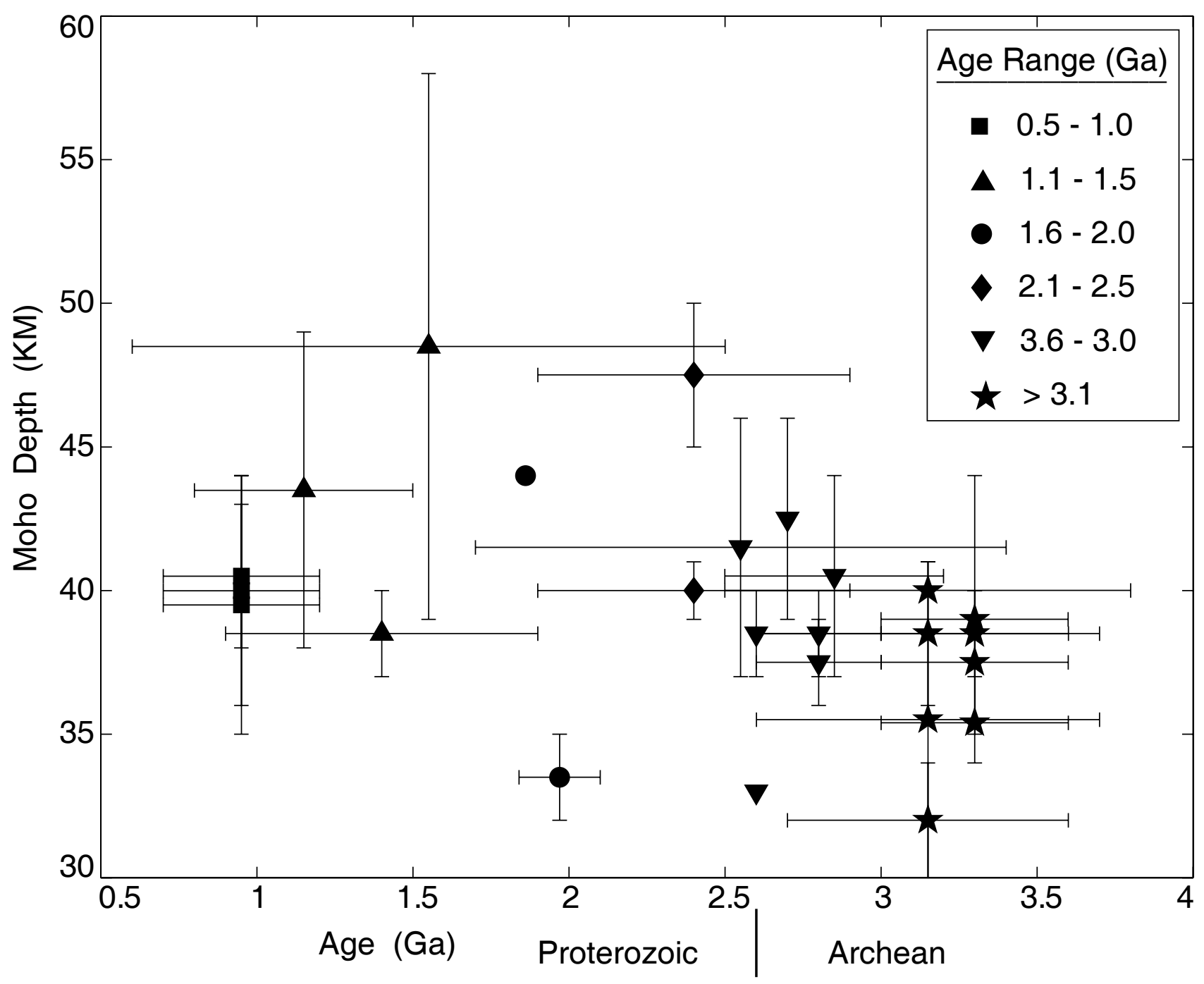

Figure 10 

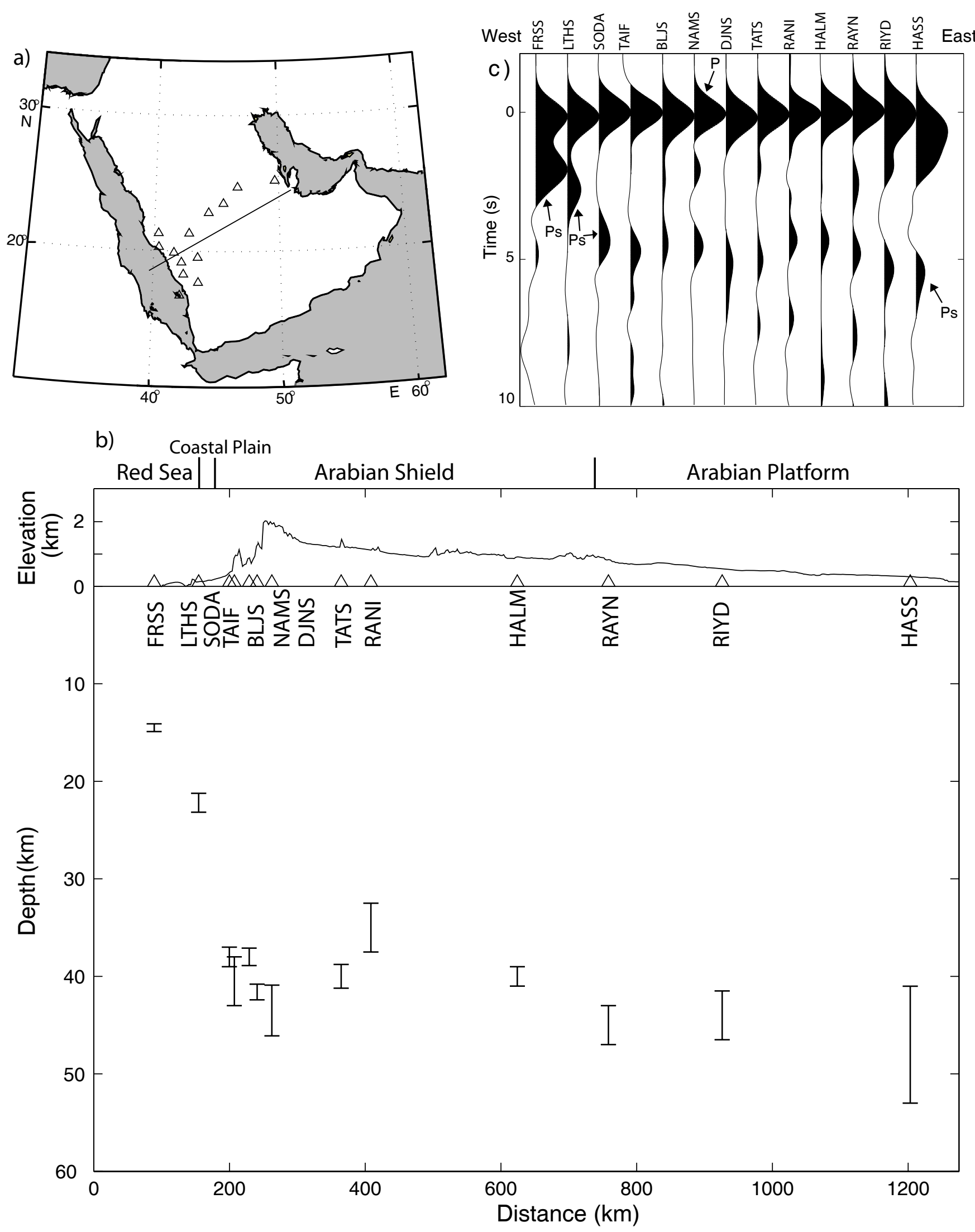

Figure 11 


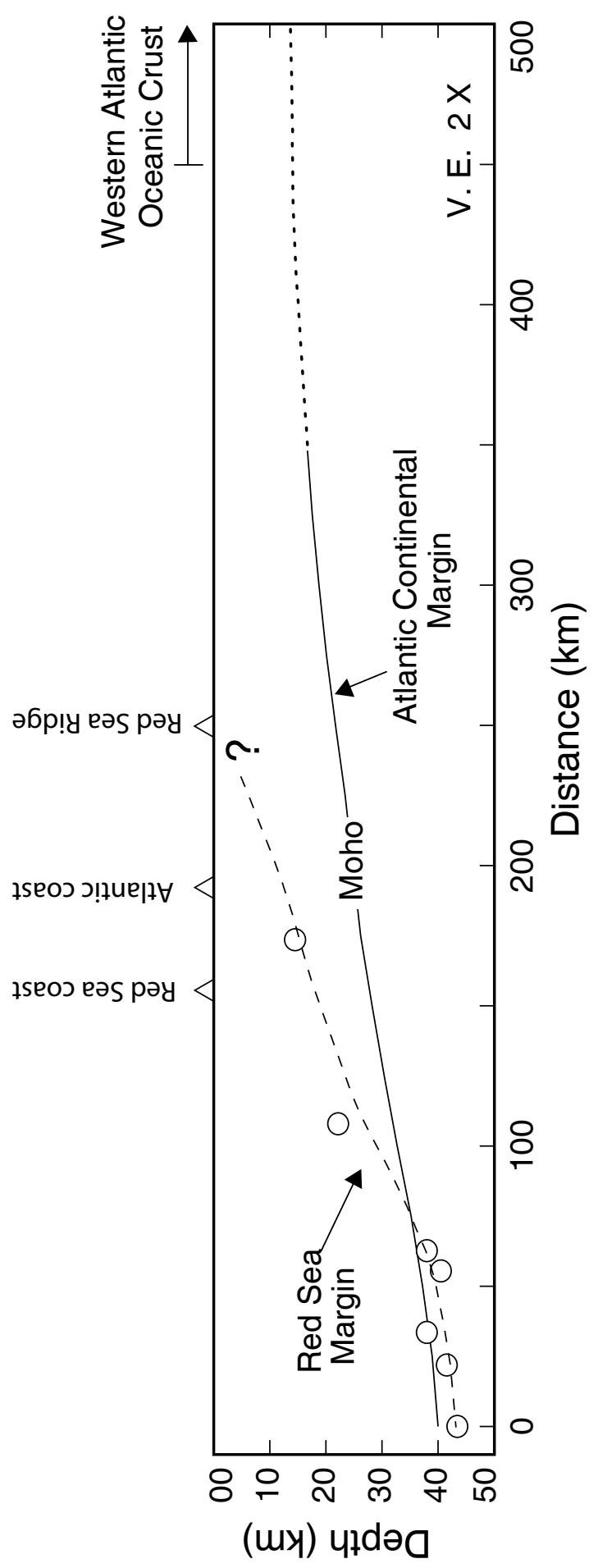

Figure 12 


\section{List of Tables:}

Table 1: A list of the seismic stations used in this study as well as this study's receiver function results. It should be noticed that the errors presented here are based on statistical re-sampling methods (bootstrap) and reflect the consistency in our data. Certainly the actual total error in determining the absolute Moho depth by any geophysical method might exceed these numbers.

Table 2: Moho depth estimates for seismic stations in the region based on receiver function results (after Sandvol et al. [13, 19] and Al-Lazki et al. [17]).

Table 3: Moho depth and age for the Arabian shield and nine other shield regions collected from different reliable studies. The ages marked by * were obtained from Goodwin [70]. Most results are based on receiver functions (RF) and only a limited number are based on very reliable deep seismic soundings (DSS). 


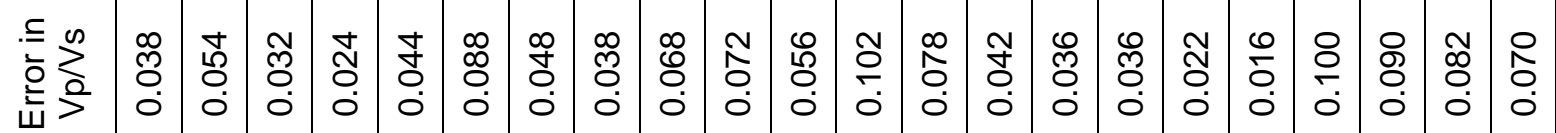

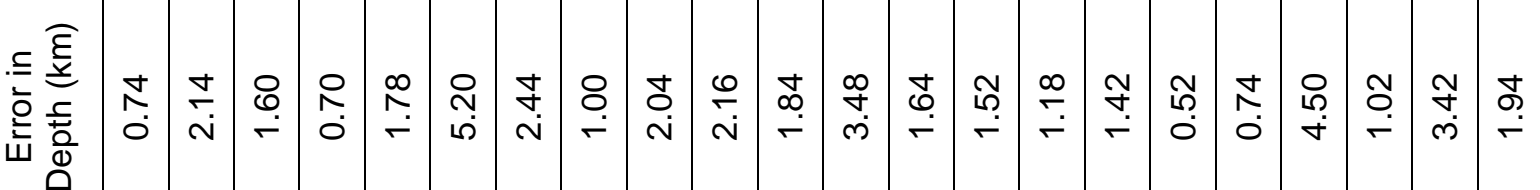

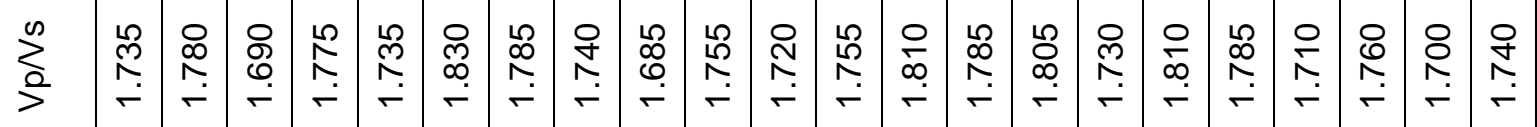

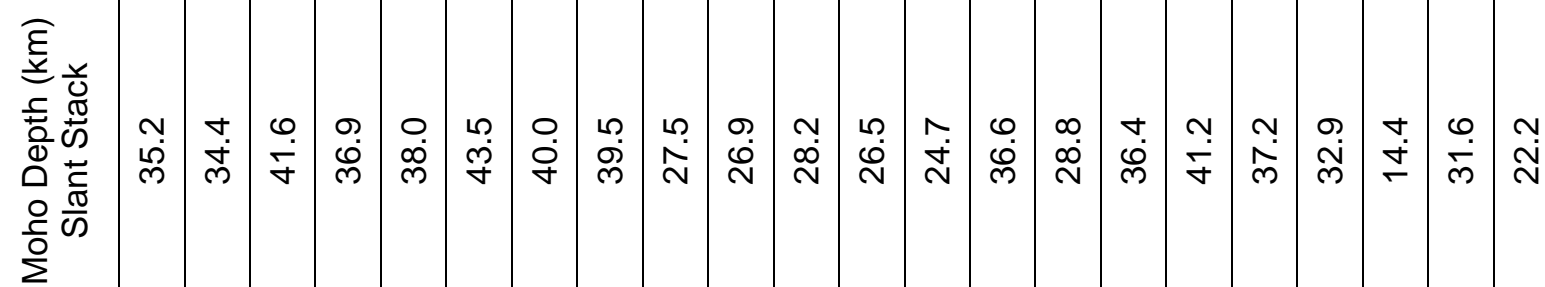

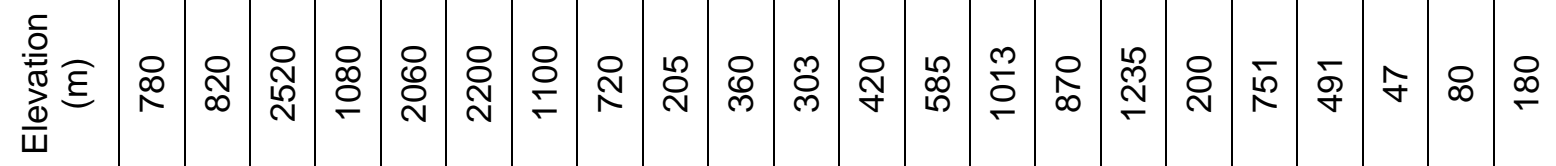

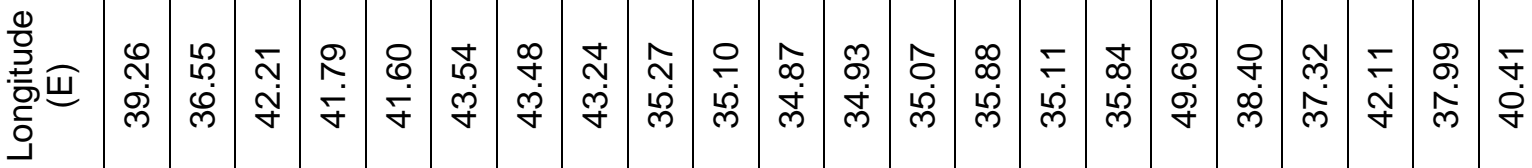

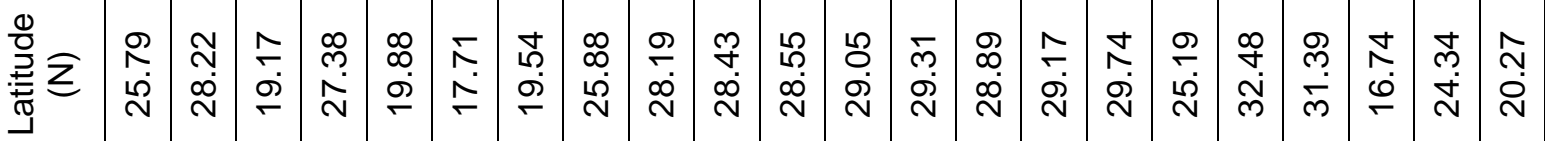

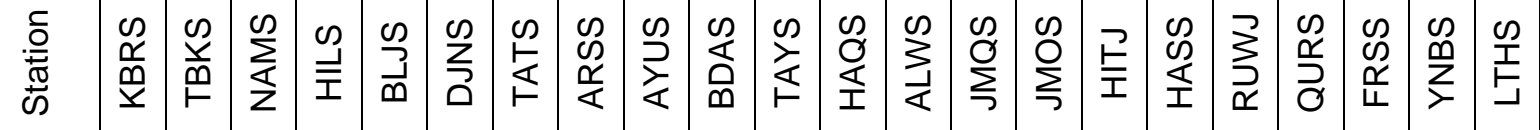

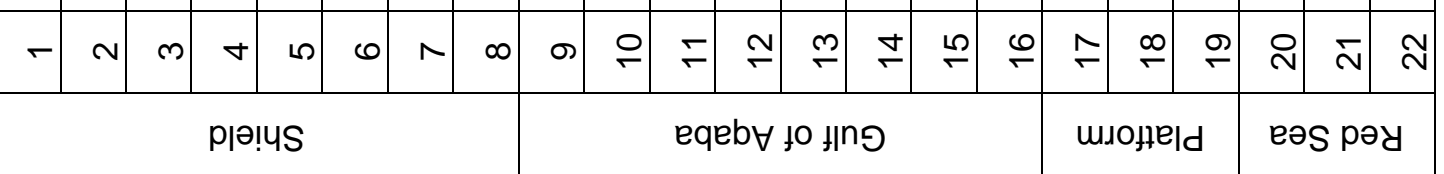


Table 2

\begin{tabular}{|l|c|c|c|c|c|}
\hline & Station & $\begin{array}{c}\text { Latitude } \\
(\mathrm{N})\end{array}$ & $\begin{array}{c}\text { Longitude } \\
(\mathrm{E})\end{array}$ & $\begin{array}{c}\text { Elevation } \\
(\mathrm{m})\end{array}$ & $\begin{array}{c}\text { Moho Depth } \\
(\mathrm{km})\end{array}$ \\
\hline 1 & AFIF & 23.93 & 43.04 & 1116 & $39.0 \pm 1.0$ \\
\hline 2 & HALM & 22.85 & 44.32 & 930 & $40.0 \pm 1.0$ \\
\hline 3 & RANI & 21.31 & 42.78 & 1001 & $35.0 \pm 2.5$ \\
\hline 4 & RAYN & 23.52 & 45.50 & 792 & $44.0 \pm 2.5$ \\
\hline 5 & RIYD & 24.72 & 46.64 & 717 & $45.0 \pm 2.0$ \\
\hline 6 & SODA & 18.29 & 42.38 & 2876 & $38.0 \pm 1.0$ \\
\hline 7 & TAIF & 21.28 & 40.35 & 2050 & $40.5 \pm 2.5$ \\
\hline 8 & UQSK & 25.79 & 42.36 & 950 & $37.0 \pm 1.5$ \\
\hline 9 & BGIO & 31.72 & 35.09 & 752 & $33.0 \pm 3.3$ \\
\hline 10 & ATD & 11.53 & 42.85 & 610 & $8.0 \pm 1.5$ \\
\hline 11 & KEG & 29.93 & 31.83 & 460 & $33.0 \pm 4.1$ \\
\hline 12 & KTOM & 23.48 & 57.69 & 107 & $41.0 \pm 2.0$ \\
\hline 13 & AWBI & 23.30 & 57.53 & 397 & $19.0 \pm 2.0$ \\
\hline 14 & JBRN & 22.91 & 57.26 & 552 & $43.0 \pm 2.0$ \\
\hline
\end{tabular}




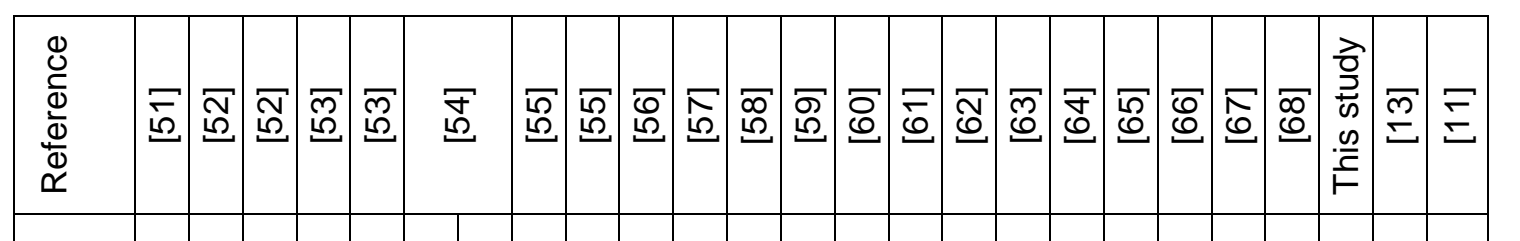

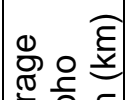

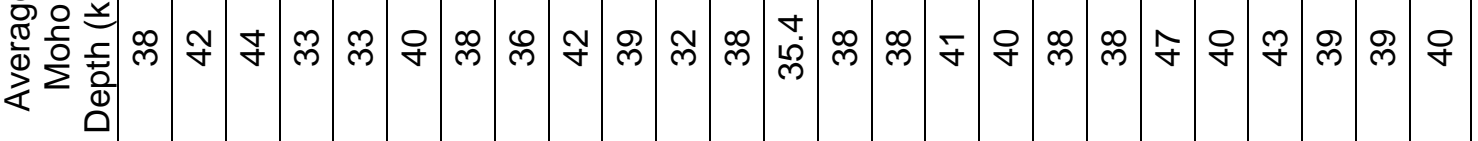

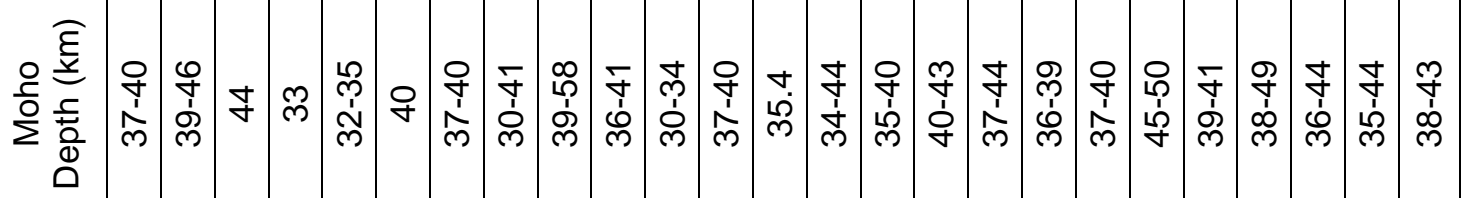

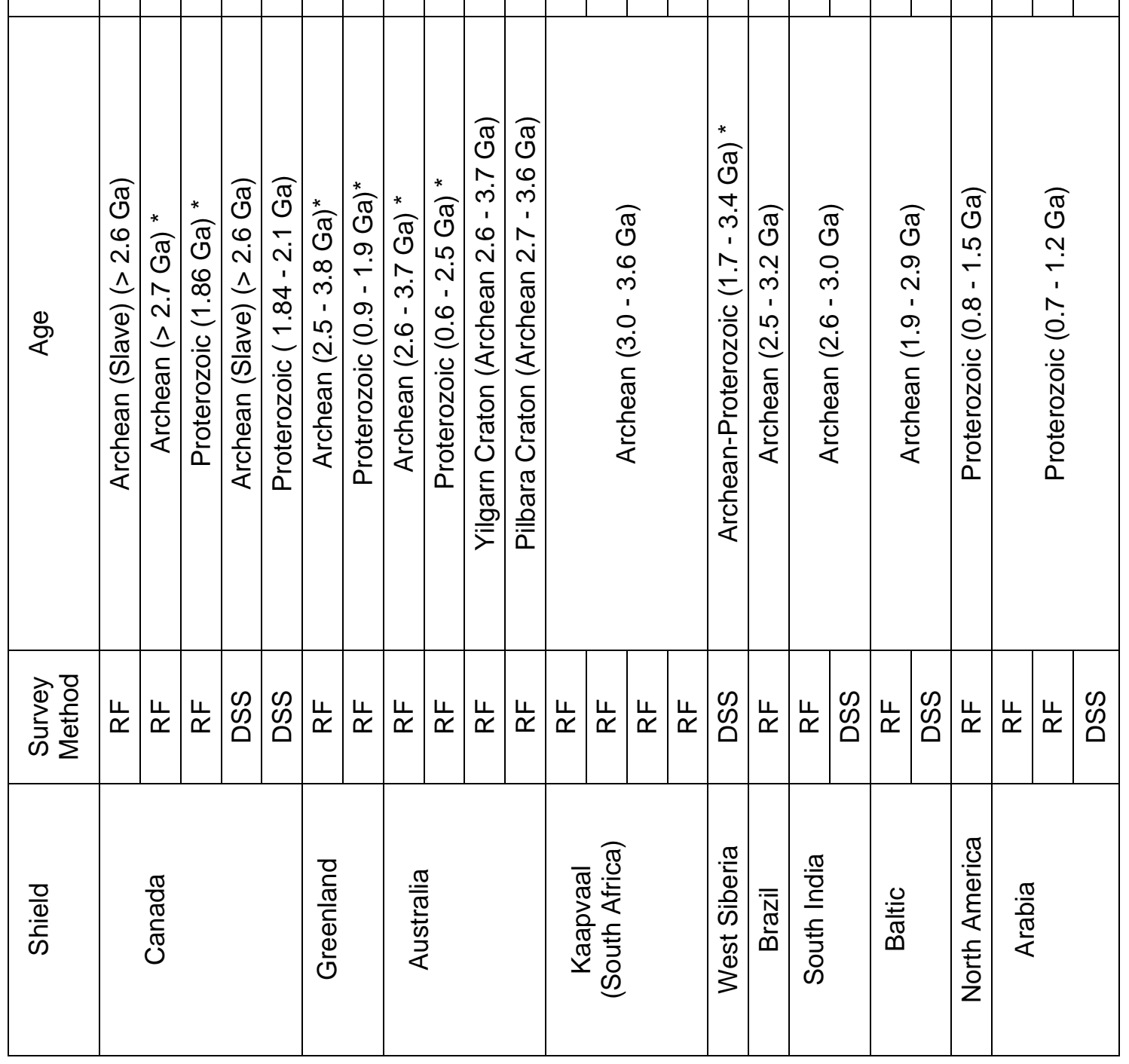


Supplementary Fig. S1. a) A map showing the epicenters (open circles) for the earthquakes used in the slant stacked receiver functions in (b). The recording station TBKS is shown by a solid triangle. b) Receiver functions corresponding to the earthquakes in (a). The two columns represent the distance $(\Delta)$ and the azimuth (AZ) in degrees for the corresponding earthquake. c) $\mathrm{H}$ vs Vp/Vs plot showing our estimated Moho depth (+) and the bootstrap error analysis results (x).

Supplementary Fig. S2. a) A map showing the epicenters (open circles) for the earthquakes used in the slant stacked receiver functions in (b). The recording station HILS is shown by a solid triangle. b) Receiver functions corresponding to the earthquakes in (a). The two columns represent the distance $(\Delta)$ and the azimuth (AZ) in degrees for the corresponding earthquake. This is a shield station and one of the best stations in terms of noise level and the running time.

Supplementary Fig. S3. a) Map showing the epicenters (open circles) for the earthquakes used in the slant stacked receiver functions in (b). The recording station TAYS is shown by a solid triangle. b) Receiver functions corresponding to the earthquakes in (a). The two columns represent the distance $(\Delta)$ and the azimuth (AZ) in degrees for the corresponding earthquake. c) $\mathrm{H}$ vs Vp/Vs plot showing our estimated Moho depth (+) and the bootstrap error analysis results (x). d) The resulting waveform synthetic fit (dashed line) using the grid search technique and the observed stacked receiver functions (solid line). e) Jackknife shear velocity models obtained from resampled receiver function stacks. The dark line indicates the mean model and the thin 
lines indicate the maximum and minimum models. Thinner crust has been observed along Gulf of Aqaba compared to the shield and platform. We observed good agreement in Moho depth between the slant stacking and the grid search results.

Supplementary Fig. S4. a) A map showing the epicenters (open circles) for the earthquakes used in the slant stacking of receiver functions in (b). The station HASS is shown by a solid triangle. b) Receiver functions corresponding to the earthquakes in (a). c) $\mathrm{H}$ vs Vp/Vs plot showing our estimated Moho depth (+) and the bootstrap error analysis results (x). d) The resulting waveform synthetic fit (dashed line) using the grid search technique and the observed stacked receiver functions (solid line). We had difficulty in modeling and slant stacking the receiver function results for station HASS. Both methods give results varying from $41 \mathrm{~km}$ to $53 \mathrm{~km}$, with poor fit for the grid search as well as extremely high $\mathrm{Vp} / \mathrm{Vs}$ values for the slant stack. 


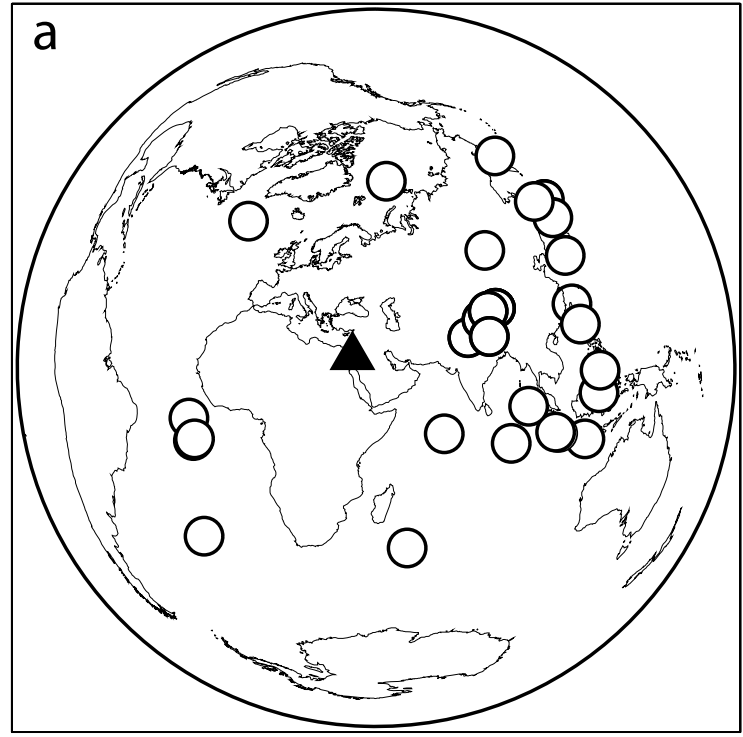

TBKS station

( 32 earthquakes )

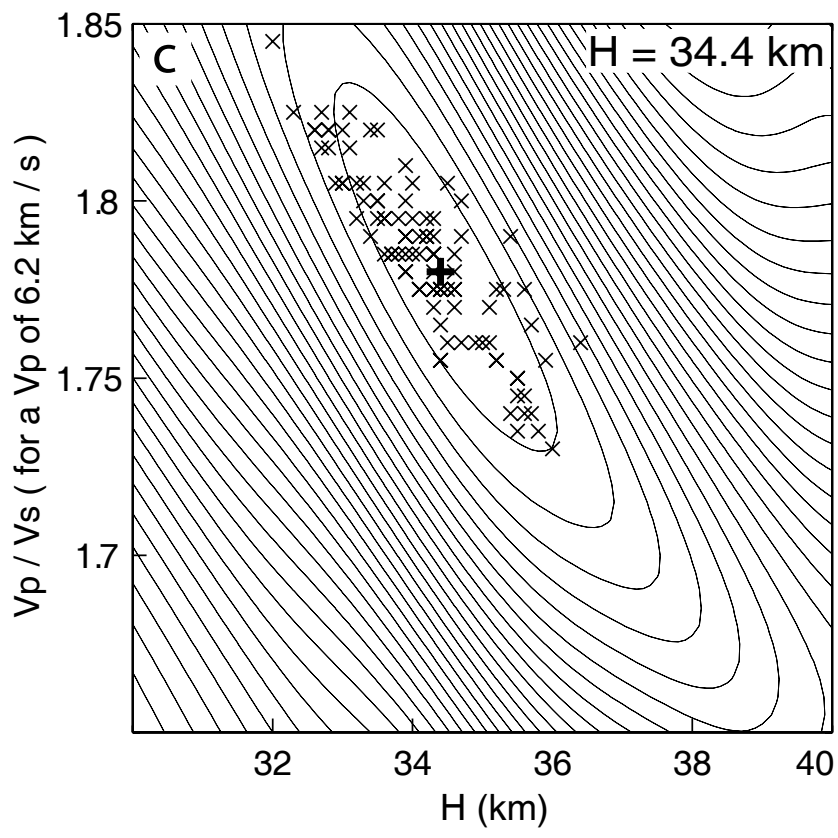

b

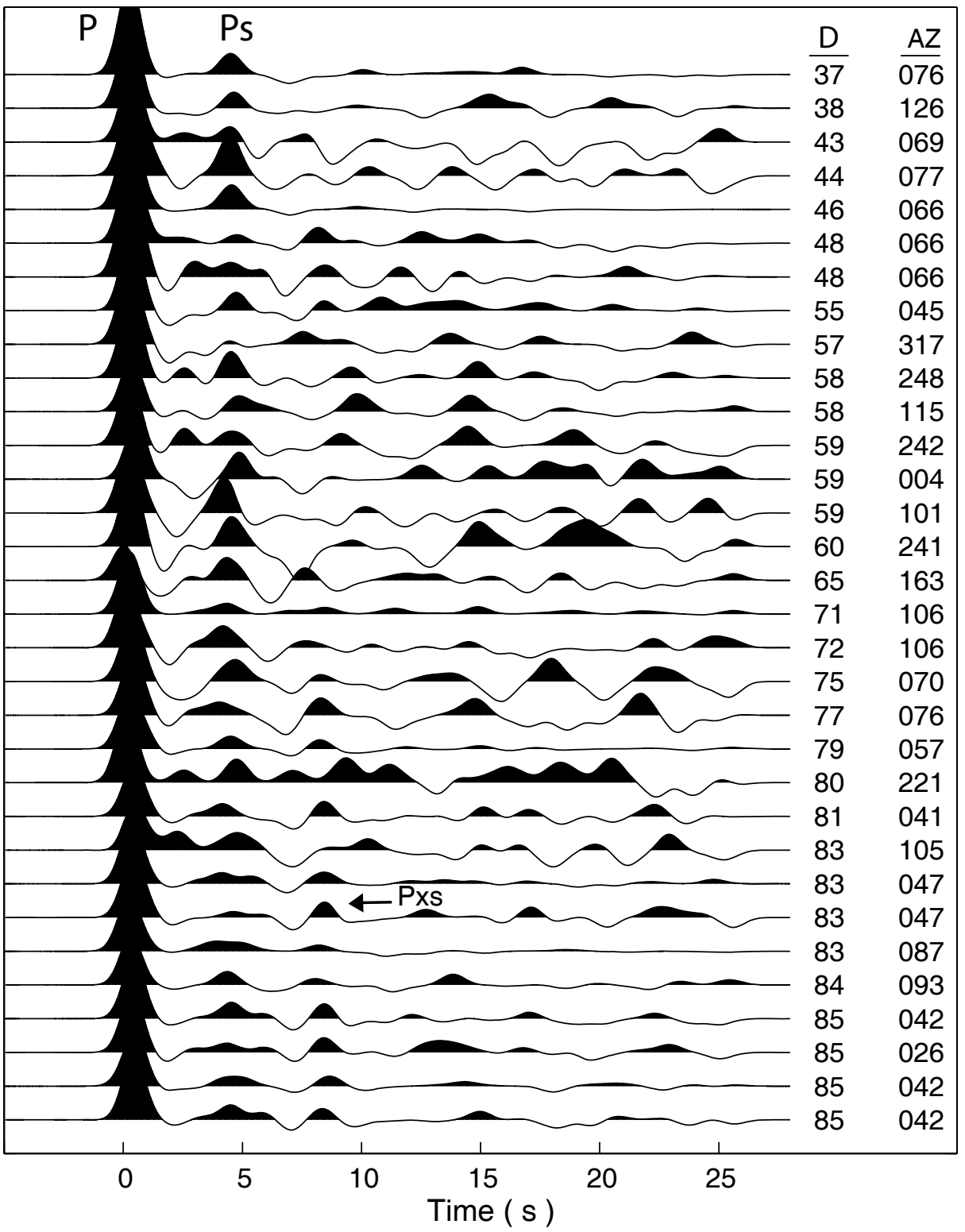

Supplementary Figure S1 


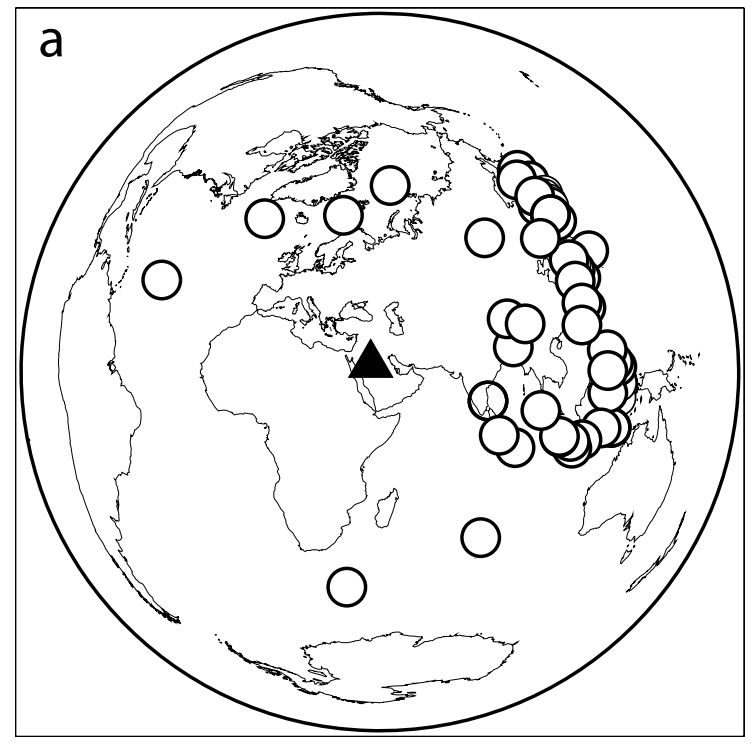

HILS station ( 55 earthquakes )

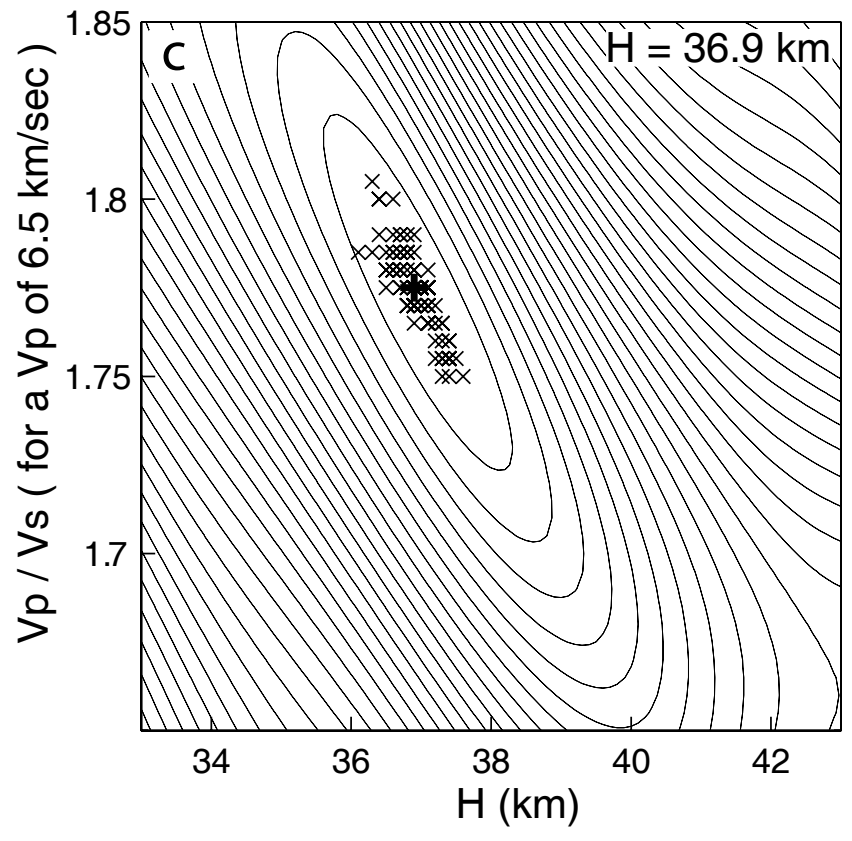

b

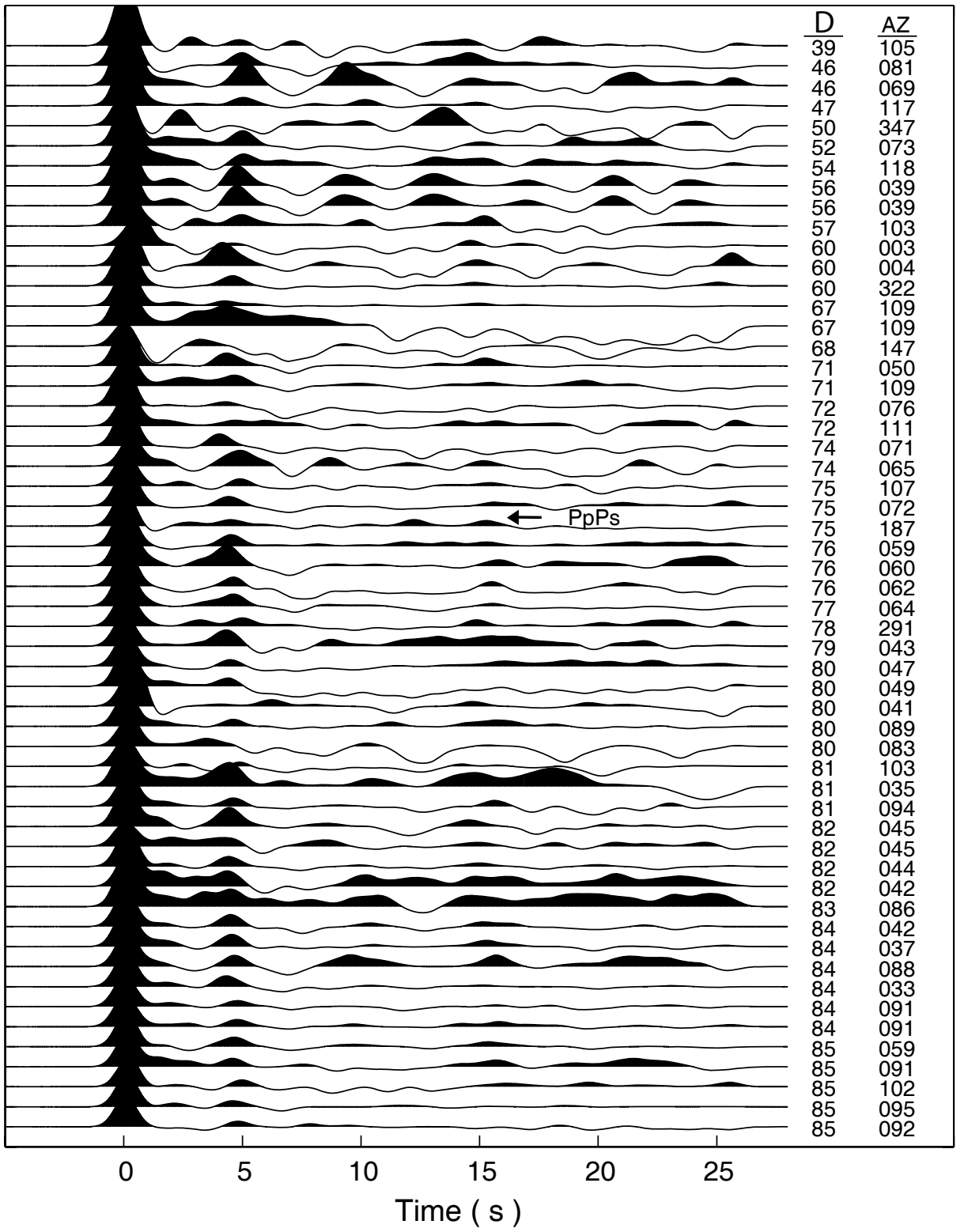



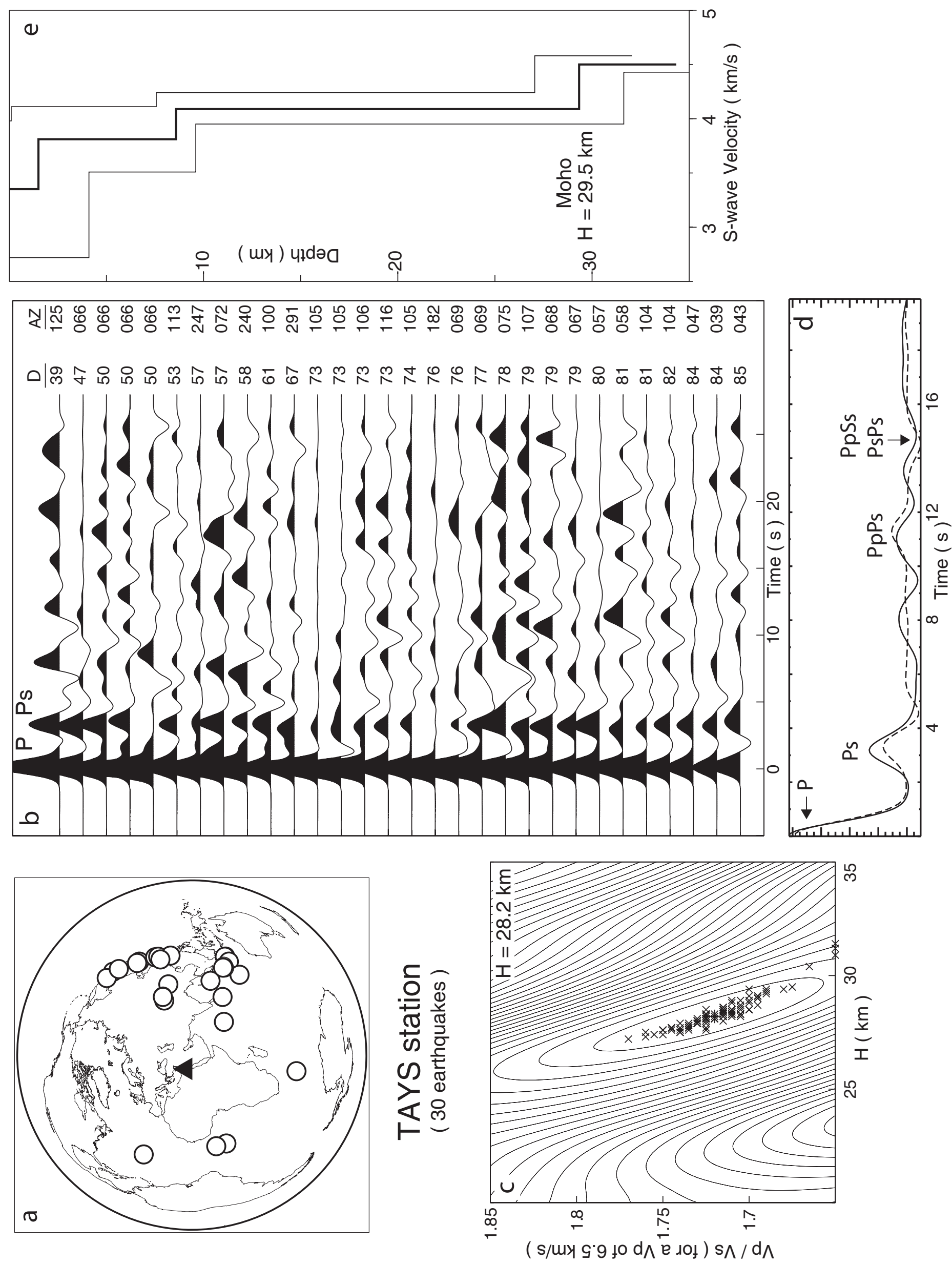

Supplementary Figure S3 


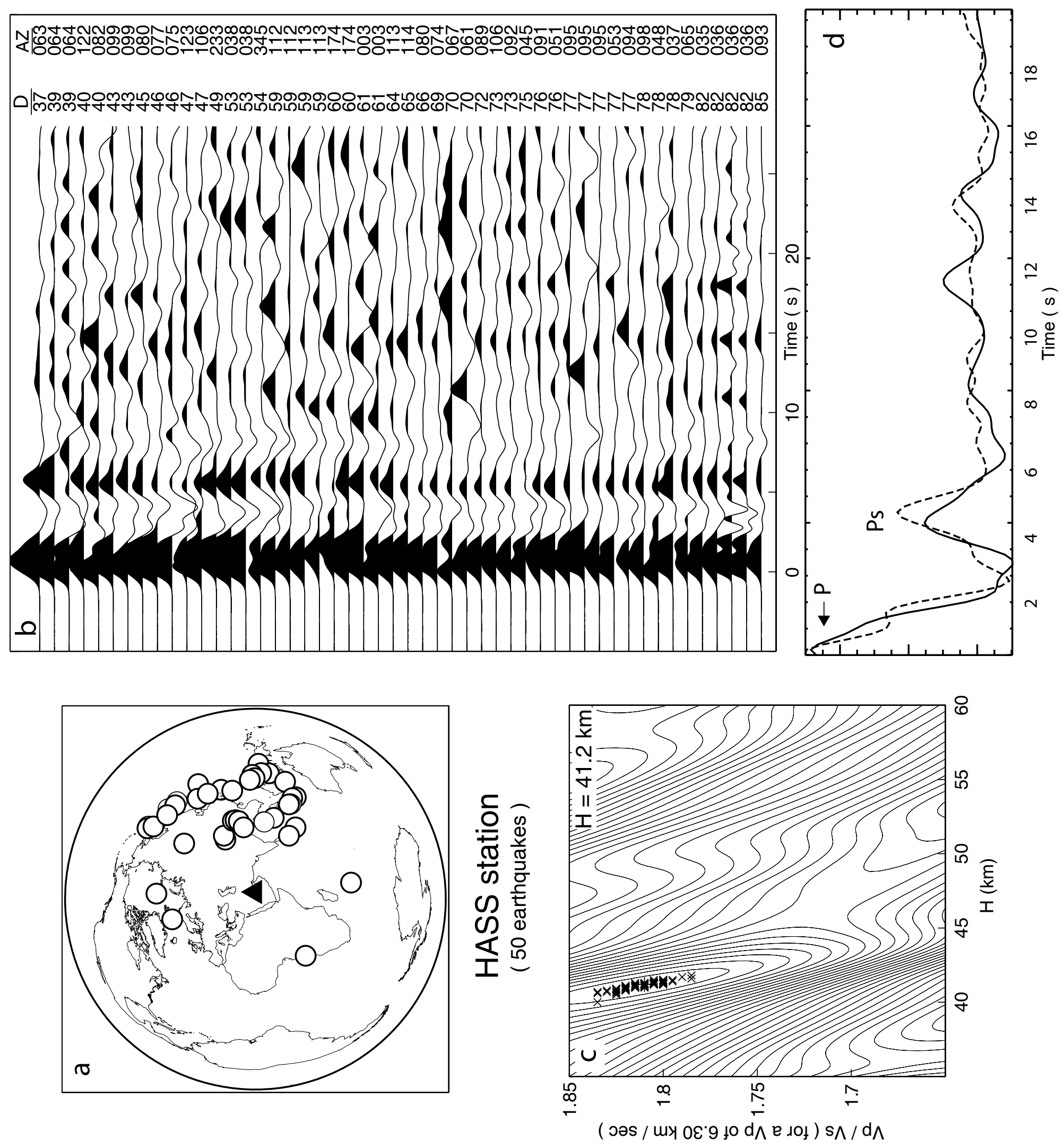

